\title{
An approach to combine radar and gauge based rainfall data under consideration of their qualities in low mountain ranges of Saxony
}

\author{
N. Jatho, T. Pluntke, C. Kurbjuhn, and C. Bernhofer \\ Institute of Hydrology and Meteorology, Department of Meteorology, Technische Universität Dresden, Dresden, Germany
}

Received: 29 April 2009 - Revised: 12 February 2010 - Accepted: 20 February 2010 - Published: 11 March 2010

\begin{abstract}
An approach to combine gauge and radar data and additional quality information is presented. The development was focused on the improvement of the diagnostic for temporal (one hour) and spatial $\left(1 \times 1 \mathrm{~km}^{2}\right)$ highly resolved precipitation data. The method is embedded in an online tool and was applied to the target area Saxony, Germany. The aim of the tool is to provide accurate spatial rainfall estimates. The results can be used for rainfall run-off modelling, e.g. in a flood management system.

Quality information allows a better assessment of the input data and the resulting precipitation field. They are stored in corresponding fields and represent the static and dynamic uncertainties of radar and gauge data. Objective combination of various precipitation and quality fields is realised using a cost function.

The findings of cross validation reveal that the proposed combination method merged the benefits and disadvantages of interpolated gauge and radar data and leads to mean estimates. The sampling point validation implies that the presented method slightly overestimated the areal rain as well as the high rain intensities in case of convective and advective events, while the results of pure interpolation method performed better. In general, the use of presented cost function avoids false rainfall amount in areas of low input data quality and improves the reliability in areas of high data quality. It is obvious that the combined product includes the small-scale variability of radar, which is seen as the important benefit of the presented combination approach. Local improvements of the final rain field are possible due to consideration of gauges that were not used for radar calibration, e.g. in topographic distinct regions.
\end{abstract}

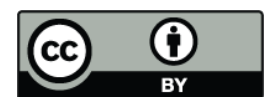

Correspondence to: N. Jatho (nadine.jatho@tu-dresden.de)

\section{Introduction}

Precipitation is the most important parameter for hydrologists and water resource engineers, especially since frequency and intensity of heavy rains increased in Saxony (Bernhofer et al., 2008) which seems to be an ongoing trend (Alcamo et al., 2007). Special regard is given to mountainous catchment areas, where steep slopes and short flow paths cause local flash floods. Thus, an efficient real-time flood forecasting requires improvements of the applied hydrological models as well as of the precipitation input.

Many national and international studies focus on the determination of the most accurate spatial rainfall product. In situ measurements are used to obtain the actual amount of rainfall at individual locations. Nowadays, it is possible to provide the data in a very high temporal resolution (up to one minute). But, as discussed by Cherubini et al. (2002) as well as by Ballester and Moré (2007), an accurate representation of the spatial distribution of rainfall requires a high-resolution network. Curtis (1996), Fuchs et al. (2001), Michelson (2004) and Sevruk (2004) analysed problems of local measurements of less than one hour, daily and monthly resolutions. Nešpor and Sevruk (1999) investigated wind errors and showed that the wind errors strongly vary with atmospheric conditions and precipitation type. Furthermore, the location of gauges strongly influence their representativeness, which is also known as site error (German and Joss, 2001; Villarini et al., 2008). As a result, spatially limited high rain intensities of short duration (convective precipitation) can be determined or remains undiscovered. Advective precipitation covers larger areas and is characterized by a more homogeneous distribution of rain intensity (Houze, 1997) and thus is mostly detected by gauge measurements.

The use of local gauge measurements as input for hydrological modelling requires in most cases spatial interpolation of the data. Here, statistical and non-statistical techniques can be distinguished. For the latter, assumptions have to be

Published by Copernicus Publications on behalf of the European Geosciences Union. 
made about spatial correlations of the considered data. Statistical methods analyse the variances between two values as well as the distance between them. Hinterding (2003), Haberlandt et al. (2005), and Pluntke et al. (2010) apply kriging methods to small and large-scale rainfall events with resolutions from one hour to several days. These methods show good results regarding the delineation of precipitation areas, but not for the internal variability within the precipitation fields and the rain intensities. Here, the quality of interpolation results strongly depends on the station density.

The importance of radar-born precipitation products as input for hydrological modelling increased during the last years, because of their high spatial and temporal resolution. Aniol and Riedl (1979), Krämer (2008) as well as Villarini and Krajewski (2010) discussed measurement errors like uncertainties in the interpretation of the radar signal as well as the influences of atmospheric parameters (e.g. temperature and wind) and topography. The correction or minimisation of these errors is a focus of ongoing radar research for the Nimrod radar system of the United Kingdom (temporal resolution: 5 and $15 \mathrm{~min}$, spatial resolution: 2 and $5 \mathrm{~km}$ ), Harrison et al. (2000) and Germann et al. (2009) analysed problems of radar measurements as well as possibilities for correction, e.g. a scheme for removal of spurious radar echoes or the use of ensemble radar precipitation estimates. The correction of errors like wind speed shifted hydrometeors in case of heavy rainfall is still limited (Delrieu et al., 2000).

Harrison et al. (2000), Bartels (2004), Berne et al. (2004), and Krämer (2008) reported that the combined products of radar and rain gauges contained fewer observational errors than the individual input datasets. Harrison et al. (2000) achieved a reduction of the root mean square difference between gauge and radar measurements of $30 \%$. Borga et al. (2002) showed that a successful combination of radar and rain gauge data is possible only if range effects are adjusted in the radar rainfall observations. Seo and Breitenbach (2002) combined radar and gauge measurements within a real-time procedure leading to a reduction of the systematic radar bias in the cold season between 16 and $27 \%$ and in the warm season between 17 and $26 \%$ as well as a reduction of the mean squared error between 34 and $46 \%$ and between 23 and $31 \%$.

The combination of spatial radar and gauge data requires the application of data assimilation concepts. Observations are combined with so-called Background (first guess) information. The Background results from climatic conditions, the output of a previous analysis, simulations of a forecast model (Bouttier and Courtier, 2002) or radar data (Pereira Fo and Crawford, 1999). The actual analysis output is considered to be the best estimate. Further analysis steps optimise the estimations with the objective to minimise data uncertainties. For more details see Bouttier and Courtier (2002) as well as Wergen (2002). The statistical objective analysis (SOA) belongs to the group of assimilation methods. Background-fields are used to reduce the error variances of ob- served gauge measurements. Pereira Fo and Crawford (1999) adopted the SOA-method and used temporally and spatially highly resolved radar data as Background. Gerstner and Heinemann (2008) adopted these studies for real-time precipitation estimation for short time intervals.

The aim of our work is to combine spatial gauge and radar data under consideration of their qualities and provide a more accurate rainfall diagnostic product for hydrological modelling in real-time. During operation, our tool determines the current precipitation type based on radar precipitation fields. Errors of the data which could not be treated beforehand, respectively uncertainties, are considered within data specific quality fields. In a cost function we combine the grid based precipitation and quality fields by weighting the different rain retrievals dependent on their quality. The algorithm generates a grid based precipitation and quality field.

Our approach represents a modification of SOA. We combined interpolated gauge data (provided by the German Weather Service, DWD, and the Saxon State Ministry of the Environment and Agriculture) from a relatively dense network (observation) with hourly radar precipitation data (Background). The radar data (RADOLAN) are already online-adjusted with gauge data from the DWD (Bartels, 2004). The use of the additional gauge information enhances the reliability of rain amounts given by radar data. The combination is realised by the online precipitation diagnosis tool, developed for this study.

The current study is divided into five sections: Section one gives an overview about state of the art of precipitation analysis and limitations using radar and gauge data for realtime precipitation estimation. Within this context the section presents the motivation, aims and approaches of the present study. Section two provides information about the study area as well as the investigated precipitation data. Section three introduces to the applied methodologies of rainfall diagnostic with emphasis on rainfall classification, statistical assessment of rainfall data, quality analysis of input data and an approach to combine several precipitation and quality products. The results of the study for selected time periods and two case studies are presented in chapter four. In the last section (Sect. 5) the results are discussed and an outlook for future research is given.

\section{Study area and data}

This section gives an overview about the study area, the precipitation sources and the investigated rainfall events.

\subsection{Study area}

The target area Saxony is located in the southeast of Germany (Fig. 1). In the northern part of Saxony are lowlands, the central part is hilly and the southern part is covered by low mountain ranges, consisting mainly of the Ore Mountains. 


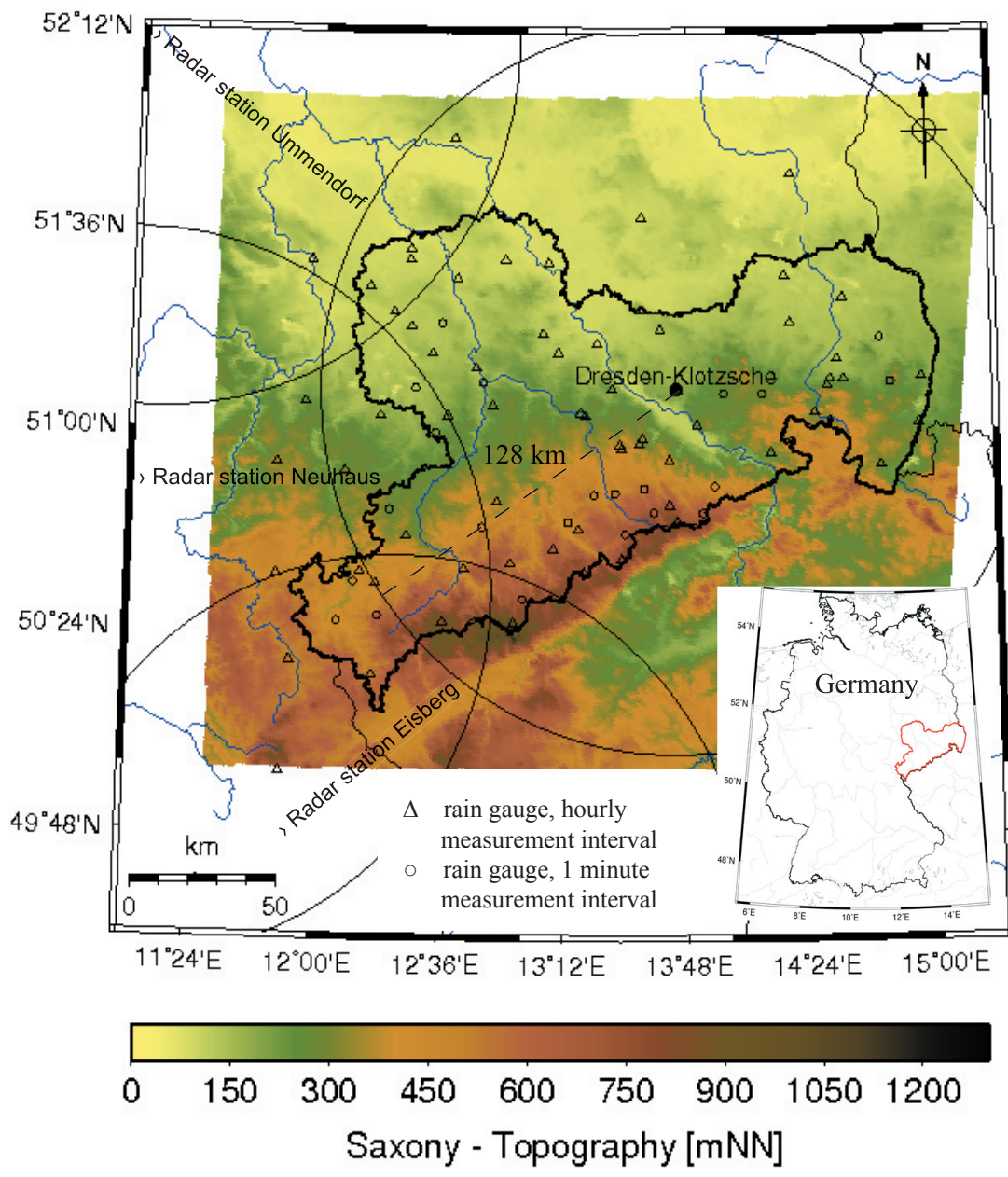

Fig. 1. Investigation area covered by the radar station Dresden-Klotzsche and adjacent stations of Bavaria, Thuringia, Saxony-Anhalt and 1-min as well as hourly gauge data. The hourly stations (with a few exceptions) are used for the online calibration of radar data.

The Fichtelberg $(1214.6 \mathrm{~m})$ is the highest mountain in the study area. Focus of our investigations lies on the hilly regions and the low mountain ranges. Here, the flood problem is more pronounced, because precipitation intensities are often higher, and steep topographic gradients cause surface runoff. Floods of mountainous catchments are characterised by pronounced flood peaks and short lead time.

\subsection{Data}

\subsubsection{Rain gauges}

We used precipitation data from 67 rain gauge stations within an area of about $18000 \mathrm{~km}^{2}$. The data were provided by the DWD and the Saxon State Ministry of the Environment and Agriculture. The temporal resolution ranges from one minute to one hour. Data with higher temporal resolutions were accumulated to hourly data. Most precipitation data were provided in real-time. Measurements were not corrected for systematic errors, because the actual wind field at the station was unknown in most cases. Gauge data were interpolated with the Background-Field (BGF) method. The applied method utilises typical precipitation fields, which base upon past hourly and daily gauge data, the general weather situation, the season as well as topographic information. Actual hourly events are interpolated with detrended kriging using the most appropriate precipitation field (BGF) as the deterministic component of this rainfall event. A basic BGF is used, if no appropriated precipitation field was found in the existing pool. The precipitation amount is evenly distributed (all grid cells are allocated with one) in the basic BGF. That causes that no secondary information enters into the detrended kriging method. Instead, ordinary kriging is applied. The BGF method is described by Hinterding (2003) and was applied to Saxony (Pluntke et al., 2010). The method reproduces the spatial structure of precipitation cells of hourly rainfall well and works reliably in real-time. 


\subsubsection{Weather radar}

Rainfall measurements by radar provide quantitative rainfall information with high temporal and spatial resolution. In general, radar precipitation data are no direct measurements, only the reflection of electromagnetic waves from falling droplets within a certain volume is determined. The most commonly used method to describe the relationship between reflectivity $(Z)$ and rain rate $(R)$ is the so-called $Z-R$ relationship (Eq. 1), where the coefficients $a$ and $b$ are empirical. They vary depending on the given rainfall situation.

$Z=a R^{b}$

High rain intensities result in a severe attenuation of the radar signal (Rinehart, 2004). Thus, within a convective cell radar measurements can be insufficient.

The DWD provides hourly precipitation data based on measurements with a $C$-band Doppler radar. Shadowing effects, rain intensity adapted Z-R relationships, statistical clutter filtering and other features are handled within an online calibration process (Bartels, 2004). In addition, derived precipitation intensities are online calibrated with ground station measurements. The so-called RADOLAN RW product represents a final precipitation product, which is hourly available as a composite consisting of 16 German and some foreign radar stations (e.g. Nancy/France). An area-wide coverage of radar data is provided for Germany and the adjacent areas with a spatial resolution of $1 \times 1 \mathrm{~km}^{2}$ (Bartels, 2004). The radar station Dresden-Klotzsche $\left(13.75^{\circ} \mathrm{E}\right.$ and $51.13^{\circ} \mathrm{N}$ ) covers the main part of the investigation area (Fig. 1). The inclusion of adjacent station data of the federal states Bavaria, Thuringia and Saxony-Anhalt allows for a complete coverage of the study area.

The temporal offset of $10 \mathrm{~min}$ between gauge and radar observations has to be noticed. We used hourly gauge data (e.g. 01:00 UTC), $1 \mathrm{~min}$ highly resolved data (aggregated to hourly sums) and combined them with RADOLAN data, which were available $10 \mathrm{~min}$ before (e.g. 00:50 UTC).

\subsection{Considered rainfall events}

For diagnostic we chose mostly heavy rainfall events from May to August 2006 and January 2007, a 16 days lasting period from 26 July to 11 August 2006 as well as a three month period from 1 May to 31 July 2009. We classified the events into convective or advective cases and investigated the precipitation data and their characteristics. Two case studies were analysed in detail (convective: 16 June 2006, 14:00 UTC, advective: 27 May 2006, 17:00 UTC).

\section{Methodology of rainfall diagnostic}

In this section, we present the applied method for rainfall classification. We studied the different errors in rainfall estimation methods based on gauge and radar measurements,
Table 1. Definition of Wetted Area Ratio (WAR) and Area Ratio of rain intensity up to $10 \mathrm{~mm} / \mathrm{h}$ (10AR) values for assignment of different precipitation types: convective (con.) and advective (ad.).

\begin{tabular}{lll}
\hline $\begin{array}{l}\text { Precipitation } \\
\text { type }\end{array}$ & WAR $[-]$ & 10AR $[-]$ \\
\hline con. & $0.0<\mathrm{WAR} \leq 0.5$ & $0.05<10 \mathrm{AR} \leq 0.7$ \\
ad. & $0.25<\mathrm{WAR} \leq 1.0$ & $0.0<10 \mathrm{AR} \leq 0.05$ \\
\hline
\end{tabular}

applied a statistical assessment and introduce an approach to handle uncertainties. The spatial gauge and radar precipitation data are combined taking into account their qualities within a cost function.

\subsection{Rainfall classification}

An accurate classification of the rainfall event into convective (here: in connection with vertical airflow, accompanied by local short-term showers, thunderstorms) or advective (here: in connection with horizontal airflow, large-scale long-term precipitation with moderate intensities) is in our opinion fundamental for a successful rainfall diagnostic. Radar data are often used for rainfall classification (Sempere-Torres et al., 2003; Ehret, 2003) and the established methods work almost reliable. We chose the radar based classification method, developed by Ehret (2003) and calculated the parameters Wetted Area Ratio (WAR) and the Area Ratio (AR) of rain intensity with more than $10 \mathrm{~mm} / \mathrm{h}(10 \mathrm{AR})$ for the study area. WAR defines the ratio of the area with precipitation intensities greater than $1 \mathrm{~mm} / \mathrm{h}$ to the whole raining area of the considered radar image, whereas 10AR is the proportion of WAR, where precipitation exceeds $10 \mathrm{~mm} / \mathrm{h}$. Both parameters are used to define, which rainfall type dominates the current event. Ehret (2003) distinguished six rainfall types and we simplified this method to a coarse classification discriminating only convective or advective precipitation (Table 1). Attention was paid, that no undefined parameter constellations arise to guarantee the system stability of our online tool. Thus, advective type is assigned as default, if parameter WAR and 10AR do not allow explicit classification.

The proof of temporal stability of the event classification using WAR and 10AR is done by means of five stability indices from radio sounding data (stations: Lindenberg, Essen, Stuttgart and Meiningen). The results are compared with the classification of WAR and 10AR for an area of $120 \times 120 \mathrm{~km}^{2}$ around four radar stations (Berlin, Essen, Türkheim, Neuhaus). The choice of investigated areas takes into account the influence of topography on the sounding data (Steinheimer and Haiden, 2007).

The definition of atmospheric stability based on sounding data is done by means of the parameters Convective Available Potential Energy (CAPE), K Index (KI), Lifted 
Table 2. Thresholds for stability indices Convective Available Potential Energy (CAPE), K Index (KI), Lifted Index (LI), Showalter Index (SI) and Total Totals Index (TT) for the assignment of different precipitation types: convective (con.) and advective (ad.).

\begin{tabular}{|c|c|c|}
\hline \multirow{2}{*}{$\begin{array}{l}\text { Stability } \\
\text { index }\end{array}$} & \multicolumn{2}{|c|}{ Threshold [-] } \\
\hline & con. & ad. \\
\hline CAPE & $>500$ & $\leq 500$ \\
\hline $\mathrm{KI}$ & $>27$ & $\leq 27$ \\
\hline LI & $<-1$ & $\geq-1$ \\
\hline SI & $<-1$ & $\geq-1$ \\
\hline TT & $>52$ & $\leq 52$ \\
\hline
\end{tabular}

Index (LI), Showalter Index (SI) and Total Totals Index (TT) (Peppler, 1988; Van der Velde, 2007). The thresholds for the five sounding parameters (Table 2) are needed for the description of the atmospheric condition. They are derived based on the studies of Kunz (2007), Dimitrova et al. (2009), Peppler (1988), Pineda et al. (2007), Queralt et al. (2008), and Sánchez et al. (2003). The sounding indices at 00:00 UTC and 12:00 UTC were checked against the corresponding radar results (hh:mm-50 UTC) for the period from 1 May to 31 July in 2009.

\subsection{Statistical assessment of data}

The main problems of a grid based rainfall diagnostic are the measurement principles and the spatial representatives of estimated gauge and radar rainfall data as well as the comparability of both data sources. Falling rain drops can be detected by radar, although they never reach the ground. Furthermore, the influence of wind drift can lead to an increasing horizontal drift of hydrometeors. The influences of several atmospheric errors of gauge measurements are discussed in detail by Nešpor and Sevruk (1999), Michelson (2004), and Sevruk (2004). Collier (1999) and Quirmbach (2003) analysed the influence of these errors on radar data. We assume that radar data can complement gauge detected rain (i.e. in case of convective event). In due consideration of meteorological influences on radar data, we implemented an assessment based on the deterministic categorical scores BIAS and Heidke Skill Score (HSS) to discriminate, whether radar data should be used as additional information at gauge stations.

In order to detect spatial offsets between, radar and gauge measurements, we examined the $3 \times 3$ pixel neighbourhood of each gauge station. We assumed the radar rain value with the smallest difference to the gauge value to be the corresponding rain value. Further, we used the deterministic categorical scores BIAS and HSS, as described in Wilks (2006), for the determination of the data quality. The basis of these parameters is a yes-no statement. We adjusted the scores,
Table 3. $2 \times 2$ contingency table for the determination of statistical scores BIAS and Heidke Skill Score (HSS).

\begin{tabular}{lcc}
\hline $\begin{array}{l}\text { Radar } \\
\text { (derived) }\end{array}$ & \multicolumn{2}{c}{$\begin{array}{l}\text { Gauge } \\
\text { (observed) }\end{array}$} \\
\cline { 2 - 3 } & Yes & No \\
\hline Yes & $a$ & $b$ \\
No & $c$ & $d$ \\
\hline
\end{tabular}

which were originally developed for forecast systems and use gauge measurements as observed and radar values as derived (original: forecasted) precipitation data. The grid based analysis of possible combinations between gauge and radar measurements requires a $2 \times 2$ contingency table (Table 3 ). Here, BIAS defines the ratio between the number of detected radar measurements and gauge measurements (Eq. 2):

$\mathrm{BIAS}=\frac{a+b}{a+c}$

with:

$a=$ hit: rainfall is measured by gauge and radar.

$b=$ false alarm: rainfall is measured only by radar.

$c=$ miss: rainfall is measured only by gauge.

$d=$ correct negatives: rainfall is not measured by gauge and radar.

An unbiased distribution is given when BIAS is equal to 1. If the analysis detected more radar data above the threshold than gauge values (higher average percentage of false alarms), the BIAS is greater than 1 and describes an overestimation of gauge measurements. With BIAS less than 1, more gauge measurements were detected (higher average percentage of misses) and radar underestimated gauge data.

The HSS (Eq. 3) is basically defined by the assumption of the proportion of hits. According to this definition, HSS in this study assumes that radar data are a result of a random process, but they are statistical independent from observed gauge data. HSS ranges from -1 to 1 , where 1 reflects the best analogies of hits, false alarms, misses and correct negatives of radar and gauge data. Zero means radar is equivalent to gauge (Wilks, 2006) and negative values indicates that the chance forecast (here: radar) is better.

$\mathrm{HSS}=\frac{2(a d-b c)}{((a+c)(c+d)+(a+b)(b+d))}$

Within the described $2 \times 2$ contingency table the differences in rainfall amounts, measured by gauge and radar, are not yet considered. Therefore we extended the $2 \times 2$ table by three additional precipitation ranges for advective events $(0-0.1 \mathrm{~mm} / \mathrm{h}, 0.1-2 \mathrm{~mm} / \mathrm{h}$, more than $2 \mathrm{~mm} / \mathrm{h})$ and four ranges for convective events $(0-0.1 \mathrm{~mm} / \mathrm{h}, 0.1-5 \mathrm{~mm} / \mathrm{h}$, $5-10 \mathrm{~mm} / \mathrm{h}$, more than $10 \mathrm{~mm} / \mathrm{h}$ ). Hence, threshold based 
$3 \times 3$ and $4 \times 4$ contingency tables are implemented. The definition of hits, false alarms, misses and correct negatives was adapted. Consequently, the parameters specify whether radar and gauge data, only radar data, only gauge data or no corresponding radar and gauge data were found within current precipitation range.

To get an impression of mean rain characteristic and to define, whether a skill score indicates a good agreement between radar and gauge data, we analysed the chosen events (420 h, Sect. 2.3) and calculated the BIAS and HSS. Gauge data, which were used for the radar calibration process, were omitted. The empirical derived limits are the temporal mean over all precipitation ranges of the investigated events. Our analysis resulted in a BIAS between 0.96 and 1.40 and a HSS higher than 0.55 for convective events and a BIAS between 0.91 and 1.45 and a HSS higher than 0.59 for advective events. BIAS values are in the range of the findings of Sokol (2003). No reference values were found for HSS values.

We analyse the rain events (Sect. 2.3) and found that on average the percentage of extended areas for advective and convective events is similar. Areas of convective events are less appropriate sampled (HSS: 0.55) than areas of advective events (HSS: 0.59). BIAS is more skewed in case of advective events. The reasons were found in higher differences between compared data couples (right-skewed: higher radar values, left-skewed: higher gauge values). We applied the thresholds for current work, because we assumed the analysed events as representative for real-time operation. If BIAS and HSS within the different ranges of $3 \times 3$ or $4 \times 4$ contingency table do not fulfil the mentioned criteria, agreement between radar and gauge data is marginal. As a result, no radar data are used to enhance gauge data at the specific location (for particulars see Sect. 3.4).

\subsection{Quality analysis}

The quality of both precipitation products was considered in this work as a static part capturing all uncertainties that are permanent and independent from the current conditions $\left(Q_{\text {stat }}\right)$. On the other hand the dynamic part of uncertainty was determined, that means errors of the actual dataset were accounted for. Quality is expressed within the range from zero to $100 \%$, whereas $100 \%$ represents for gauge as well as radar data the best precipitation value. Germann and Joss (2001) showed clearly (by using radar data), that representativeness of point observations depend on the degree of spatial variation (depending on time, location and integration time) and uncertainty of the single measurement.

\subsubsection{Gauge quality}

Spatial representativeness of rain gauges is regarded as the static part of the quality. It is a known fact, that precipita- tion measured with a gauge is less representative for its surrounding in case of convective events compared to advective events. Furthermore, topography determines spatial representativeness of gauges. There are various processes in mountainous regions that cause a higher spatial variability. The most important processes are topographic lifting of air masses and enhanced precipitation on the windward side of the mountain, the rain shadow on the leeward side, the diurnal convection, the seeder-feeder-effect at the windward sides of small hills etc.

There are only few investigations that focused on the spatial representativeness of rain gauges. For daily precipitation values Sevruk (2004) states that gauge measurements represent an area of two kilometres in diameter in flat regions and of one kilometre in mountainous regions. Representativeness of hourly and even higher resolved values can be much smaller, especially for thunderstorms and on top of mountains. For hourly values Gebremichael and Krajewski (2004) showed that correlation between gauges that are for example 2 and $8 \mathrm{~km}$ separated from each other dropped from 0.8 to 0.4 . Considering all rainfall events with more than $1 \mathrm{~mm} / \mathrm{h}$, Moreau et al. (2009) found that correlation reduced to 0.7 within a distance of $6 \mathrm{~km}$. For events with more than $3 \mathrm{~mm} / \mathrm{h}$ rainfall correlation decreased to 0.4 . The results of Moreau et al. (2009) and Gebremichael and Krajewski (2004) base on a limited database of one or two months. Furthermore, convective systems of Florida (USA), the Amazonas region, France and Germany are not fully comparable.

A clear limited extension of shower cells was published by the German Weather Service (DWD, 1981) for a German radar station. So, $80 \%$ of the investigated rain cells with rain intensities of $1 \mathrm{~mm} / \mathrm{min}$ and $97 \%$ of the rain cells with $2 \mathrm{~mm} / \mathrm{min}$ were smaller than $4 \mathrm{~km}^{2}$. No investigation about the representativeness of gauge measurements is known for our study area.

Although mentioned studies confirm parts of the commonly known dependencies of spatial representativeness of rain gauges on topography and rainfall type, no comprehensive and quantitative approach that is transferable to Saxony is known. We chose an empiric approach based on the findings mentioned above for our analysis, because no data of a dense gauge network were available to conduct an analysis of representativeness in our investigation area. To account for topographic differences of spatial variability, we divided the investigation area into a mountainous and a hilly domain. Zoning bases on the subdivision of Saxony into macrochores by Haase and Mannsfeld (2002) that considered, among others, topographic and climatic aspects (mountainous classification: above $250 \mathrm{~m}$ ). We assumed a decreasing representativeness of gauge data with distance to station for convective and advective events (Table 4). No variability of cell sizes was considered in our study, because we found no typical cell sizes that approximate the results of DWD (1981). 
Table 4. Static quality of rain values in dependence on distance to gauge, topography, and rain event type (convective: con. and advective: ad.).

\begin{tabular}{ccccc}
\hline \multirow{2}{*}{$Q_{\text {stat }}[\%]$} & \multicolumn{4}{c}{ Distance $[\mathrm{km}]$} \\
\cline { 2 - 5 } & \multicolumn{2}{c}{$\begin{array}{l}\text { Hilly region } \\
\text { con. }\end{array}$} & \multicolumn{2}{c}{ Mountainous region } \\
& 0.65 & 2.0 & 0.35 & 1.0 \\
& 1.4 & 4.0 & 0.65 & 2.0 \\
100 & 2.7 & 8.0 & 1.0 & 3.0 \\
70 & $\geq 3.7$ & $\geq 11.0$ & $\geq 2.0$ & $\geq 6.0$ \\
40 & &
\end{tabular}

To account for the dynamic part of gauge quality, we established a plausibility check for precipitation data of a temporal resolution between 1 and $60 \mathrm{~min}$. The following criteria were applied:

I. Threshold check for physically meaningful values. Up to mean values of $8 \mathrm{~mm} / 1 \mathrm{~min}, 40 \mathrm{~mm} / 10 \mathrm{~min}$ and $90 \mathrm{~mm} / 60 \mathrm{~min}$ the data are assigned with $Q_{\text {dyn }}=100 \%$. Rain values are flagged with zero for maximum values above $20 \mathrm{~mm} / 1 \mathrm{~min}, 60 \mathrm{~mm} / 10 \mathrm{~min}$ or $120 \mathrm{~mm} / 60 \mathrm{~min}$. In-between, $Q_{\text {dyn }}$ is the difference of maximum quality and the weighting of actual rain amount.

II. Test of constant intensities of consecutive time steps. Highest quality is allocated for up to six consecutive time steps of low rain intensities $(0.1 \mathrm{~mm} / 1 \mathrm{~min}$, $1 \mathrm{~mm} / 10 \mathrm{~min}, 1 \mathrm{~mm} / 60 \mathrm{~min})$. If the values have been unchanged for more than eight times, they are indicated as zero. In-between $Q_{\text {dyn }}$ is reduced linearly. The number of plausible constant intensities decreases with increasing precipitation amounts. E.g., if a value above $3 \mathrm{~mm} / 1 \mathrm{~min}$ is detected more than two times, it is indicated with $Q_{\text {dyn }}=0 \%$.

III. Test of physically meaningful differences between consecutive time steps. The criteria differ depending on the season (summer: April-September, winter: OctoberMarch). Highest quality is assigned to differences up to $4 \mathrm{~mm} / 1 \mathrm{~min}$ (summer), $25 \mathrm{~mm} / 10 \mathrm{~min}$ (summer), $3 \mathrm{~mm} / 1 \mathrm{~min}$ (winter) and $10 \mathrm{~mm} / 10 \mathrm{~min}$ (winter). Lowest quality is assigned to values above $8 \mathrm{~mm} / 1 \mathrm{~min}$ (summer), $35 \mathrm{~mm} / 10 \mathrm{~min}$ (summer), $7 \mathrm{~mm} / 1 \mathrm{~min}$ (winter) and $20 \mathrm{~mm} / 10 \mathrm{~min}$ (winter). In-between, $Q_{\text {dyn }}$ is reduced linearly.

IV. Test of minimal duration of a precipitation event above a certain threshold. Lowest $Q_{\text {dyn }}$ is assumed for rain amounts above $1 \mathrm{~mm} / \mathrm{h}$ and a duration of more than $2 \min$.
V. Threshold test for physically meaningful hourly values for the past $60 \mathrm{~min}$ (same criteria as described in plausibility check [I]).

Data with a resolution of 10 min were not checked for criteria (IV). Hourly data were additionally not checked for criteria (III) and (V). Mean and maximum thresholds are the result of a literature review (e.g. Bartels et al., 2005) and an analysis of long-term datasets (1 min and 10 minute: 20052008, 1 h: 1992-2008). We defined threshold ranges and no kick out criteria (worst quality is defined as zero). It is difficult to fix thresholds that reflect the conditions of the domain. It entails the risk that thresholds, which are too low, could cause an elimination of extreme values and thresholds, which are too high, would not allow detecting data errors. Data were aggregated to hourly values, whereas missing values were replaced. Here, a minimum of 49 values for 1-min and 5 for 10-min values was required to aggregate them to an hourly value. A quality in the range of zero and $100 \%$ was assigned to hourly data as a result of the plausibility check. Only precipitation data with a quality $\left(Q_{\text {dyn }}\right)$ greater than zero were considered for further analysis.

The local $Q_{\text {dyn }}$ was used to enhance the spatial station representativeness $Q_{\text {stat }}$. Here, the static quality field was reduced by the difference that resulted from the differences of $Q_{\text {dyn }}$ and $Q_{\text {stat }}$ at the stations. A multiplicative procedure to combine both qualities would result in somewhat higher quality. Because we had no mean to validate the performance of both procedures, we chose the subtraction procedure. An hourly quality field resulted from this combination (compare Figs. 9b and 11b).

\subsubsection{Radar quality}

The accurate interpretation of the reflectivity signal is essential for the quality of rainfall estimation (Rinehart, 2004). The provided radar data (Sect. 2.2.2) already passed several procedures (e.g. correction of default values, correction of attenuation based on precipitation intensity, correction of topographic influences, improved $Z-R$ relationship). But the adaption of correction methods is still difficult for the real-time processing of data (Bartels, 2004). Therefore we quantified potential errors within a quality field. The static field $\left(Q_{\text {stat }}\right)$ results from the attenuation effect (decreasing data quality with increasing distance to the radar station). Combining the results of Delrieu et al. (2000), Krämer (2008), and Gerstner and Heinemann (2008) a quality reduction of $20 \%$ for a maximum distance of $128 \mathrm{~km}$ is assumed for the applied radar data and stored into the $Q_{\text {stat }}$ field (Fig. 2).

The dynamic quality criterion $\left(Q_{\text {dyn }}\right)$ was derived from actual differences between gauge and radar data. The steps to derive the dynamic quality field were:

1. Within a $3 \times 3$ pixel neighbourhood around each gauge station the radar rain value with the smallest difference 


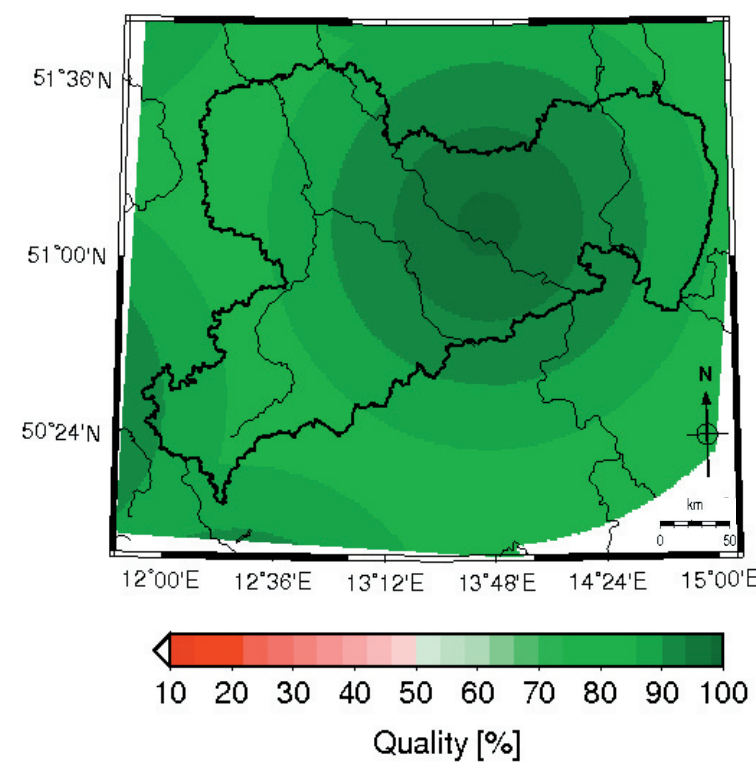

Fig. 2. Static quality field ( $\left.Q_{\text {stat }}\right)$ of radar data.

to the gauge value was assumed to be the corresponding value.

2. An empirical quality between 10 and $100 \%$ was assigned to encountered differences between radar and gauge data. We allocated a quality of $100 \%$ for differences between gauge and corresponding radar data below $10 \%$. For more than $40 \%$ difference, a quality of $10 \%$ was assigned. The low data quality is assigned to take into account, that the statistical errors also increase (Sokol, 2003). In-between values were calculated by a linear approach at the sampling points.

3. The empirical qualities were interpolated applying Inverse Distance Weighting (IDW) onto the radar grid and represent the dynamic quality field $Q_{\text {dyn }}$.

The validity of $Q_{\mathrm{dyn}}$ Radar depends on the number of available gauge stations. If only a few gauges deliver values for an actual event, the interpolation of the empirical qualities is critical. Due to the high spatial variability of rainfall and the complex error characteristic of radar data, we assume that the differences between radar and gauge are only valid for a limited area around the gauge. We followed the study of Ballester and Moré (2007) and replaced $Q_{\text {dyn }}$ by $Q_{\text {stat }}$ if less than eight stations are available.

\subsection{Data combination}

We combined our precipitation and quality fields within a SOA. As described by Pereira Fo and Crawford (1999), radar data were used as Background and the rain gauge data as the observed part. Similar to Gerstner and Heinemann (2008) we modified the basic analysis equation of the SOA technique (cost function) for our real-time requirements:

$P(x, y)=\sum_{i=1}^{n}\left(P_{i}(x, y) w_{i}(x, y)\right)$

Precipitation in a grid cell $P(x, y)$ is calculated as the sum of the products of different grid based precipitation sources $\left(P_{i}\right)$ with their corresponding weighting fields $\left(w_{i}\right)$. The minimisation of background error-variance within a cross correlation (between gauge and radar data) as described by Pereira Fo and Crawford (1999) was replaced by the application of the derived quality fields (radar quality: $Q_{\mathrm{r}}$, gauge quality: $\left.Q_{\mathrm{g}}\right)$. The relations between radar $\left(w_{\mathrm{r}}\right)$ and gauge weighting $\left(w_{\mathrm{g}}\right)$ depending on $Q_{\mathrm{r}}$ and $Q_{\mathrm{g}}$ are described in detail by the following equations:

$w_{\mathrm{r}}(x, y)=k^{\left(\left(100-Q_{\mathrm{r}}\right) / 10\right)}\left(l Q_{\mathrm{g}}^{2}+m Q_{\mathrm{g}}+n\right)$

$w_{\mathrm{g}}(x, y)=1-w_{\mathrm{r}}(x, y)$

Equation (5) represents a quadratic function, whereas the first term represents the adjustment of the weighting function depending on the actual radar quality. The second term includes the weighting in dependence on gauge quality. Whenever one rainfall product (radar or gauge data) was unknown or failed, that means its quality equals zero, the remaining product was weighted with one (Eqs. 5 and 6). We tested the functionality of Eq. (5) based on several couples of radar and gauge data with hourly resolution, for different atmospheric conditions and distances, and determined the empirical parameters $l, m, n$, and $k$ for convective situations (with $l=-0.00007, m=-0.0002, n=0.9932, k=0.9)$ and for advective situations (with $l=-0.0001, m=-0.0008, n=0.9994$, $k=0.9$ ). For example, Eq. (5) results in a higher weighting of radar data for convective than for advective events, caused by the limited representativeness of gauge measurements.

Figures 3 and 4 show the radar weighting functions for convective and advective rainfall events. Note the point where the curves cross the $100 \%$ line of $Q_{\mathrm{g}}$. Due to high variability of atmospheric parameters, as discussed in Curtis (1996), Fuchs et al. (2001), Michelson (2004), and Sevruk (2004) we assumed that a gauge is not able to represent the precipitation of one $1 \times 1 \mathrm{~km}^{2}$ pixel, especially during highly convective rainfall. Thus, the use of the spatially highly resolved information of the radar could lead to a better approximation of the rain amount within this pixel. To reduce the influence of radar data with low quality when combining with the measured gauge value $\left(Q_{\mathrm{g}}=100 \%\right)$, only radar data were considered that do not exceed the prescribed limits of BIAS and HSS (described in Sect. 3.2). For $Q_{\mathrm{g}}=100 \%$ a weight up to $30 \%$ (convective situation) or up to $2 \%$ (advective situation) is assigned to the radar data, if radar data are used to correct gauge values at location. The weighting for the advective case is lower, because it is assumed that the pixel is much better represented by a gauge. If $Q_{\mathrm{g}}$ is $100 \%$ 


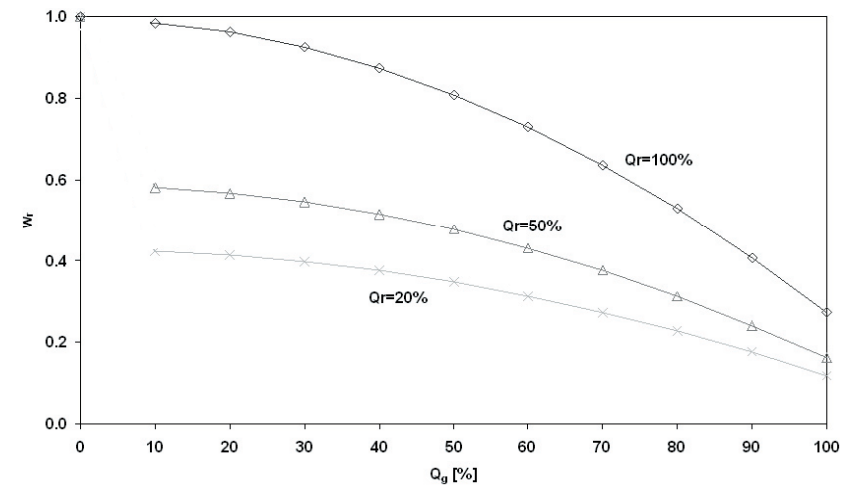

Fig. 3. Radar weights $\left(w_{\mathrm{r}}\right)$ based on radar $\left(Q_{\mathrm{r}}\right)$ and gauge $\left(Q_{\mathrm{g}}\right)$ qualities in case of convective precipitation events.

and no radar data are available or the values of BIAS and HSS do not exceed prescribed limits, radar weighting is set to $w_{\mathrm{r}}=0$. Furthermore noticeable is the step of the curves for $Q_{\mathrm{g}}$ less than $10 \%$ in Figs. 3 and 4. This gap is to ensure that in case of very poor or missing gauge data the sum of the weightings equals one.

The final quality product $Q(x, y)$ can be calculated using Eq. (4), just replacing $P_{i}(x, y)$ with the quality fields $Q_{i}(x, y)$.

We used the cross validation method for the analysis of the applied methods. The gauge measurements (stations are excluded, which are part of the Radolan procedure) were directly compared with pure interpolated gauge data, pure radar data and the combined precipitation value. We used the Bias $_{\mathrm{CV}}$ (not to be confuse with the BIAS skill score mentioned before) (Eq. 7) and the root-mean-squared error (RMSE) (Eq. 8) as criteria. Low Bias ${ }_{\mathrm{CV}}$ values indicate a good reproduction of the average areal precipitation, whereas low RMSE values reflect, that higher rain intensities were captured well. In Eqs. (7) and (8) $p_{i}$ describes the estimated and $o_{i}$ the observed value.

$\operatorname{Bias}_{\mathrm{CV}}=\frac{1}{n} \sum_{i=1}^{n}\left(p_{i}-o_{i}\right)$

$\mathrm{RMSE}=\sqrt{\frac{1}{n} \sum_{i=1}^{n}\left(p_{i}-o_{i}\right)^{2}}$

\section{Results}

We analysed three convective and three advective short-term precipitation events (Table 5), which have durations of two or three hours and two case studies (convective: 16 June 2006, 14:00 UTC, advective: 27 May 2006, 17:00 UTC). No quality reduction resulted from the plausibility check of the gauge values for the considered events.

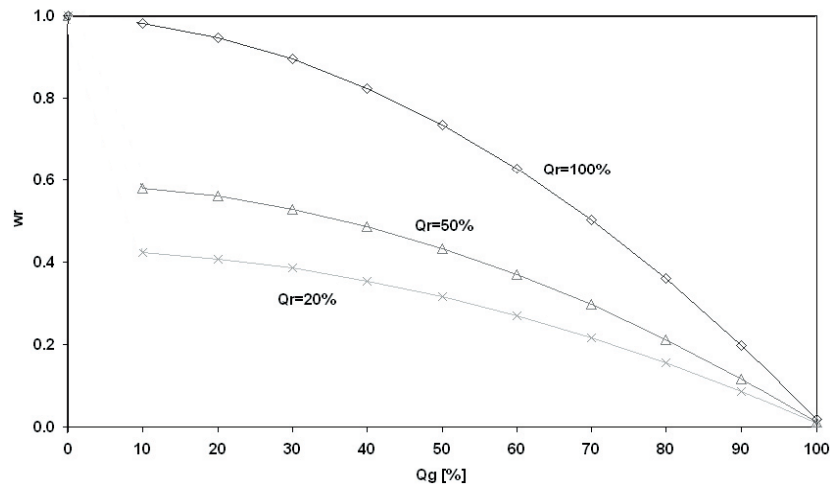

Fig. 4. Radar weights $\left(w_{\mathrm{r}}\right)$ based on radar $\left(Q_{\mathrm{r}}\right)$ and gauge $\left(Q_{\mathrm{g}}\right)$ qualities in case of advective precipitation events.

\subsection{Investigations of short and long-term periods}

Maximum rainfall of radar was $100 \%$ more than gauge precipitation in case of advective events. In spite of the investigation of the $3 \times 3$ pixel neighbourhood around each gauge station, the maximum rain amounts of radar and gauge measurements were never detected in the same grid cells. We ascribed these spatial offset to the sparse density of gauge data in comparison to the spatially high resolved rain information given by radar. Gauge stations mostly detected the cells of higher rain rates at the fringe, but not the highest rain intensities in the centre. High WAR values (0.26-0.44) were determined, which represent a large precipitation area. On the other hand the Area Ratio of rain rates of more than $10 \mathrm{~mm} / \mathrm{h}$ is low (10AR: $0.00-0.01$ ).

During the convective events maximum radar rainfall intensities were on average five times higher than maximal gauge intensities (recall Table 5). The rainfall areas were mostly less expanded (WAR: 0.03-0.18) and the number of radar detected intensive rain cells was high (10AR: 0.090.31 ).

The classification of the precipitation event into convective or advective based on the parameters WAR and 10AR was cross checked by the aid of sounding indices. In flat regions (represented by the radars of Berlin and Essen) the findings show an analogy of correct classification of $76 \%$ for convective and $97 \%$ for advective condition. For the hilly regions (represented by the radars of Türkheim and Neuhaus) the accuracy is slightly lower with $73 \%$ (convective) and $95 \%$ (advective) correct classifications.

The parameters hits $(a)$, false alarms $(b)$, misses $(c)$ and correct negatives $(d)$ were analysed for long-term periods (Sect. 2.3) and short-term periods (Table 5) to identify, whether there is a dependency on the investigation period.

For the long-term investigation the average percentage of hits is between 83 and $88 \%$ in range $1(0-0.1 \mathrm{~mm} / \mathrm{h})$ for convective as well as advective events. It was higher than for the other precipitation ranges (Table 6). The ratio of false alarms 
Table 5. Investigated rain events for convective (con.) and advective (ad.) precipitation situations. Maximum precipitation intensities of radar $P_{\mathrm{r} \text { max }}$ and gauge $P_{\mathrm{g} \text { max }}$ and the event parameters (WAR, 10AR) are determined.

\begin{tabular}{lrrllll}
\hline Date & $P_{\mathrm{r} \max }$ & $P_{\mathrm{g} \max }$ & $\begin{array}{l}\text { Number } \\
\text { of gauges }\end{array}$ & WAR & 10AR & $\begin{array}{l}\text { Event } \\
\text { type }\end{array}$ \\
& {$[\mathrm{mm} / \mathrm{h}]$} & {$[\mathrm{mm} / \mathrm{h}]$} & & & & \\
\hline [UTC] & 25.30 & 8.53 & 52 & 0.42 & 0.01 & ad. \\
\hline 27 May 2006, 17:00 & 10.30 & 6.66 & 51 & 0.37 & 0.00 & $\mathrm{ad}$. \\
16 Jun 2006, 14:00 & 103.00 & 26.00 & 52 & 0.12 & 0.31 & con. \\
16 Jun 2006, 15:00 & 40.70 & 8.90 & 52 & 0.15 & 0.18 & con. \\
19 Jun 2006, 15:00 & 46.70 & 8.60 & 51 & 0.15 & 0.16 & con. \\
19 Jun 2006, 16:00 & 38.50 & 11.60 & 51 & 0.18 & 0.11 & con. \\
19 Jun 2006, 17:00 & 27.50 & 12.40 & 51 & 0.15 & 0.14 & con. \\
06 Aug 2006, 01:00 & 29.40 & 5.92 & 35 & 0.44 & 0.00 & ad. \\
06 Aug 2006, 02:00 & 12.30 & 7.13 & 35 & 0.36 & 0.00 & ad. \\
06 Aug 2006, 03:00 & 9.00 & 10.40 & 35 & 0.33 & 0.00 & ad. \\
06 Aug 2006, 15:00 & 10.10 & 16.37 & 34 & 0.26 & 0.00 & ad. \\
06 Aug 2006, 16:00 & 19.70 & 11.40 & 35 & 0.39 & 0.00 & ad. \\
06 Aug 2006, 17:00 & 21.10 & 11.68 & 35 & 0.42 & 0.00 & ad. \\
03 Jul 2009, 11:00 & 42.60 & 3.10 & 44 & 0.02 & 0.19 & con. \\
03 Jul 2009, 12:00 & 27.10 & 3.20 & 44 & 0.03 & 0.09 & con. \\
03 Jul 2009, 13:00 & 31.60 & 3.30 & 44 & 0.04 & 0.14 & con. \\
\hline
\end{tabular}

Table 6. Average percentages of hits (a), false alarms (b), misses (c) and correct negatives (d) of radar and gauge data (recall Table 2) for convective (con.) and advective (ad.) precipitation situations, for a long-term (con.: $85 \mathrm{~h}$, ad.: $335 \mathrm{~h}$ ) and a short-term period (con.: $8 \mathrm{~h}$, ad.: $8 \mathrm{~h}$ ) considering different precipitation ranges (con.: $0-0.1 \mathrm{~mm} / \mathrm{h}, 0.1-5 \mathrm{~mm} / \mathrm{h}, 5-10 \mathrm{~mm} / \mathrm{h},>10 \mathrm{~mm} / \mathrm{h}$, ad.: $0-0.1 \mathrm{~mm} / \mathrm{h}$, $0.1-2 \mathrm{~mm} / \mathrm{h},>2 \mathrm{~mm} / \mathrm{h}$ ).

\begin{tabular}{|c|c|c|c|c|c|}
\hline \multirow{3}{*}{$\begin{array}{l}\text { Precipitation } \\
\text { range }\end{array}$} & \multirow[t]{3}{*}{ Parameter } & \multicolumn{4}{|c|}{ Average percentage [\%] } \\
\hline & & \multicolumn{2}{|c|}{$\begin{array}{l}\text { Long-term } \\
\text { period }\end{array}$} & \multicolumn{2}{|c|}{$\begin{array}{l}\text { Short-term } \\
\text { period }\end{array}$} \\
\hline & & con. & ad. & con. & ad. \\
\hline \multirow[t]{4}{*}{1} & $\mathrm{a}$ & 88 & 83 & 75 & 16 \\
\hline & $\mathrm{b}$ & 0 & 0 & 0 & 0 \\
\hline & $\mathrm{c}$ & 4 & 4 & 6 & 8 \\
\hline & d & 8 & 13 & 19 & 76 \\
\hline \multirow[t]{4}{*}{2} & $\mathrm{a}$ & 6 & 8 & 10 & 36 \\
\hline & $\mathrm{b}$ & 3 & 4 & 6 & 8 \\
\hline & $\mathrm{c}$ & 1 & 2 & 4 & 11 \\
\hline & d & 90 & 86 & 80 & 45 \\
\hline \multirow[t]{4}{*}{3} & a & 1 & 3 & 2 & 26 \\
\hline & $\mathrm{b}$ & 1 & 2 & 4 & 12 \\
\hline & $\mathrm{c}$ & 0 & 0 & 0 & 1 \\
\hline & d & 98 & 95 & 94 & 61 \\
\hline \multirow[t]{4}{*}{4} & a & 0 & - & 2 & - \\
\hline & $\mathrm{b}$ & 1 & - & 2 & - \\
\hline & $\mathrm{c}$ & 0 & - & 0 & - \\
\hline & d & 99 & - & 96 & - \\
\hline
\end{tabular}

slightly increased for both event types with higher rain rates (range 2), but showed a declined tendency for ranges 3 and 4. We ascribe this effect to the existence of a higher ratio of moderate rain rates in the lower precipitation ranges.

The results of parameters $a, b, c$, and $d$ for short-term periods were similar to that of longer periods. The tendencies of decreasing hits and misses as well as increasing correct negatives from range 1 to range 4 have been retained for both event types. The average percentage of hits and misses for advective events was in range 2 double as high as in range 1. A slight reduction followed in range 3 . The tendency is reversed for the correct negatives. The results are caused by moderate rain intensities up to $2 \mathrm{~mm} / \mathrm{h}$ embedded in large extended rain cells, which were well covered by gauge measurements.

We analysed the differences between radar and gauge measurements for convective and advective events with the aid of the scores BIAS (Eq. 2) and HSS (Eq. 3). The radar data were used to improve gauge data at locations in case of low differences. For convective events BIAS is less than one for range 1 (Fig. 5). Higher rain intensities show a significant overestimation by radar (range 2 up to range 4). BIAS determination often failed for rain rates higher than $5 \mathrm{~mm} / \mathrm{h}$, because radar detected high intensity rain cells, while gauge measurements did not. During advective events (Fig. 6) radar mostly underestimate rainfall of lower intensities, where rain rates higher than $2 \mathrm{~mm} / \mathrm{h}$ are overestimated. If BIAS values are out of range (recall Sect. 3.2), no radar data are used to improve gauge data at the immediate vicinity of the station. 


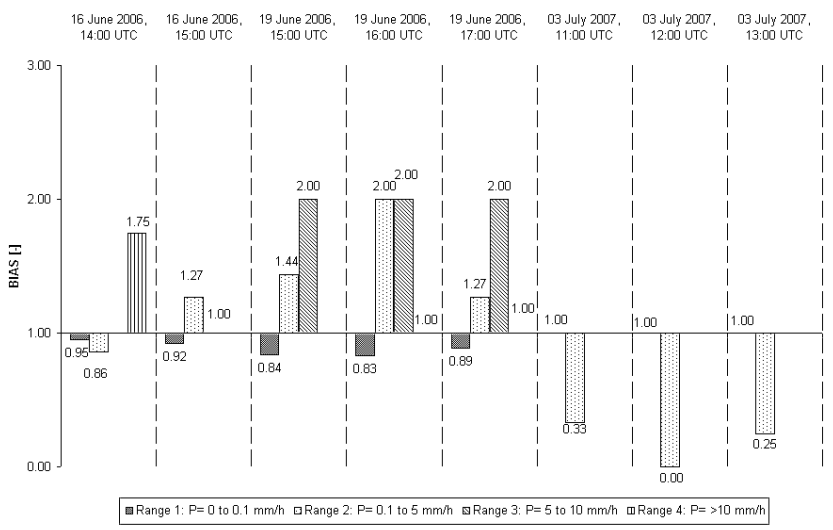

Fig. 5. The statistical score BIAS for the four precipitation ranges of the analysed convective rain events.

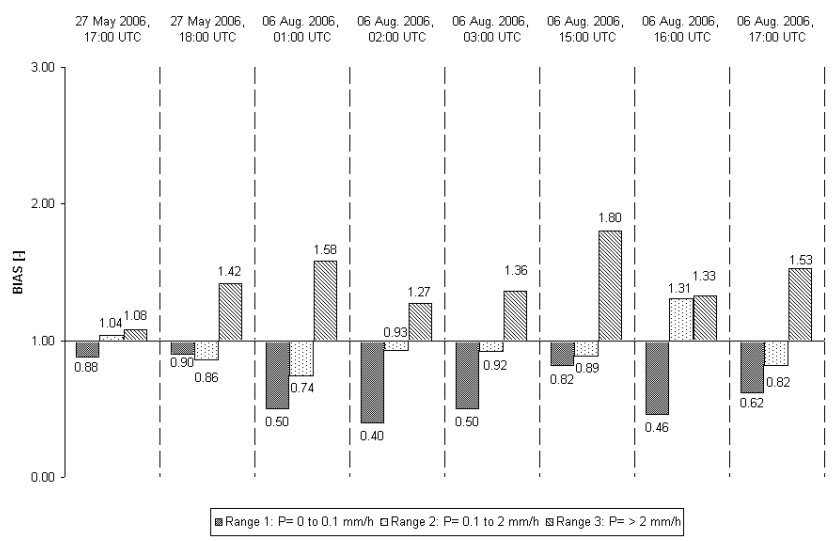

Fig. 6. The statistical score BIAS for the three precipitation ranges of the analysed advective rain events.

In addition to BIAS, the HSS (Eq. 3) considered the correct negatives (d). The determined ranges for convective events (Fig. 7) were higher than for advective events (Fig. 8). Based on long-term investigations (recall Sect. 3.2), HSS $>0.55$ (convective event) and HSS $>0.59$ (advective event) were considered as thresholds for the radar data to improve gauge data at the station.

\subsection{Case study events of 16 June 2006 and 27 May 2006}

Exemplarily, we show the results of combining gauge and radar data applying the cost function for the convective event on 16 June 2006, 14:00 UTC (Figs. 9 and 10) and for the advective event on 27 May 2006, 17:00 UTC (Figs. 11 and 12). For these days large precipitation areas exist, which are mostly well covered by gauge observations.

Strong convection led to heavy showers and thunderstorms during the analysed event on 16 June 2006, 14:00 UTC. The BGF-method delineated well the central precipitation area of the convective event (Fig. 9a), whereas two small cells in the western part were not covered by gauges. A large rain

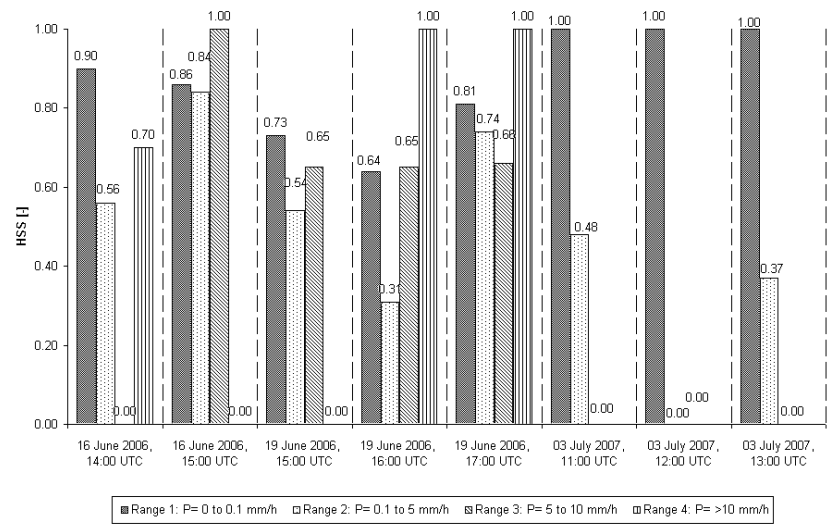

Fig. 7. The statistical score HSS for the four precipitation ranges of the analysed convective rain events.

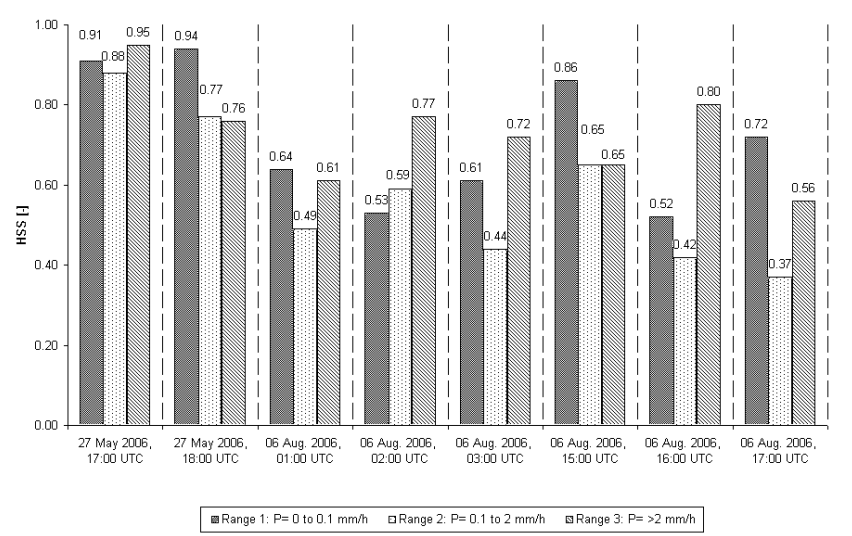

Fig. 8. The statistical score HSS for the three precipitation ranges of the analysed advective rain events.

area with high rain rates $\left(P_{\mathrm{g} \max }=26 \mathrm{~mm} / \mathrm{h}\right)$ was detected in the south of Saxony. The dimension of interpolated precipitation areas differed from radar measurements. The radar covered precipitation area in the south had a higher spatial extension to the east (Fig. 9c). In addition, maximum rain rates were significantly higher $\left(P_{\mathrm{r} \max }=103.00 \mathrm{~mm} / \mathrm{h}\right)$. Note, that the highest rain values were not detected in the same grid cells, which is reflected in a quite low correlation $(R=0.49)$ between gauge and radar values (stations used for online calibration were omitted). No clear dependence of the topographic characteristic is apparent. In Fig. 9b the large area of gauge qualities of $10 \%$ becomes obvious. This is due to the low representativeness of gauge stations for convective events. Stations represent the event in mountainous areas up to a distance of $2 \mathrm{~km}$ and in lower situated areas up to $3.7 \mathrm{~km}$. High quality uncertainties of radar data are identifiable in Fig. 9d, which are caused by large differences between radar and gauges that were not used for calibration. The spatial distribution of rainfall was better represented by radar than by gauge data. 

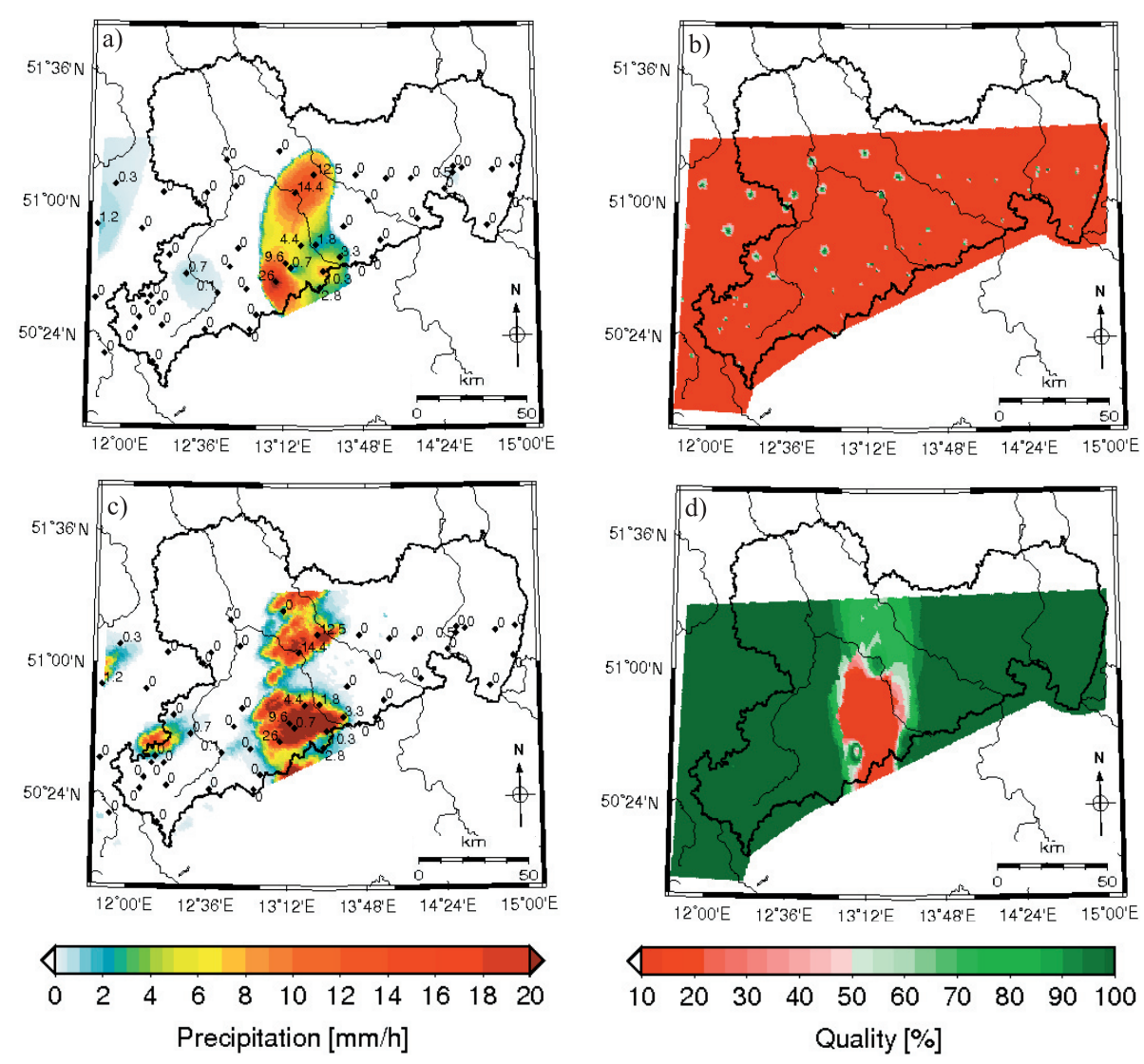

Fig. 9. Input fields (a) interpolated gauge observations and (c) hourly radar data, as well as (b) and (d) their corresponding quality fields for the convective event on 16 June 2006, 14:00 UTC.
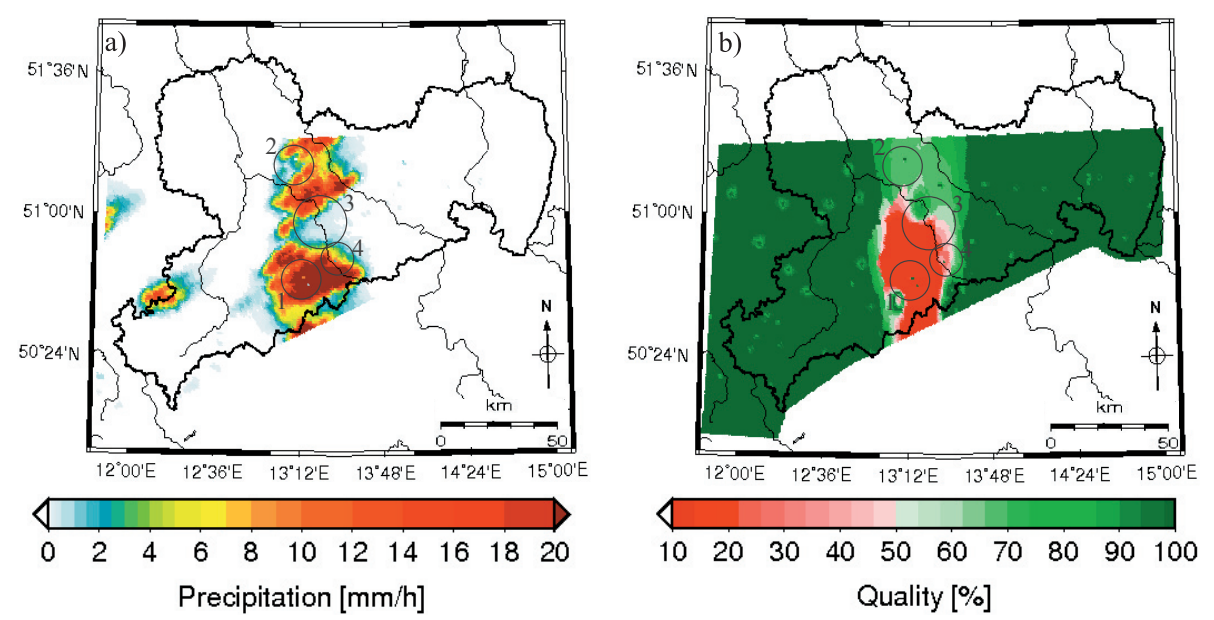

Fig. 10. Final precipitation (a) and quality (b) fields based on the combination of data with the cost function approach for the convective event on 16 June 2006, 14:00 UTC.

All BIAS values fell out of the determined range criteria. In ranges 1, 2, and 4 HSS values indicated a good correlation between radar and gauge data, but failed for third precipitation range (recall Figs. 5 and 7). BIAS and HSS values did not fulfil the required thresholds and no radar data were used to improve gauge measurements at locations with a quality of $100 \%$. However, the combination of precipitation and quality information achieved significant changes in areas with high rain intensities. The comparison between Fig. 10a and $b$ shows that gauge data with low rain amounts and of good 

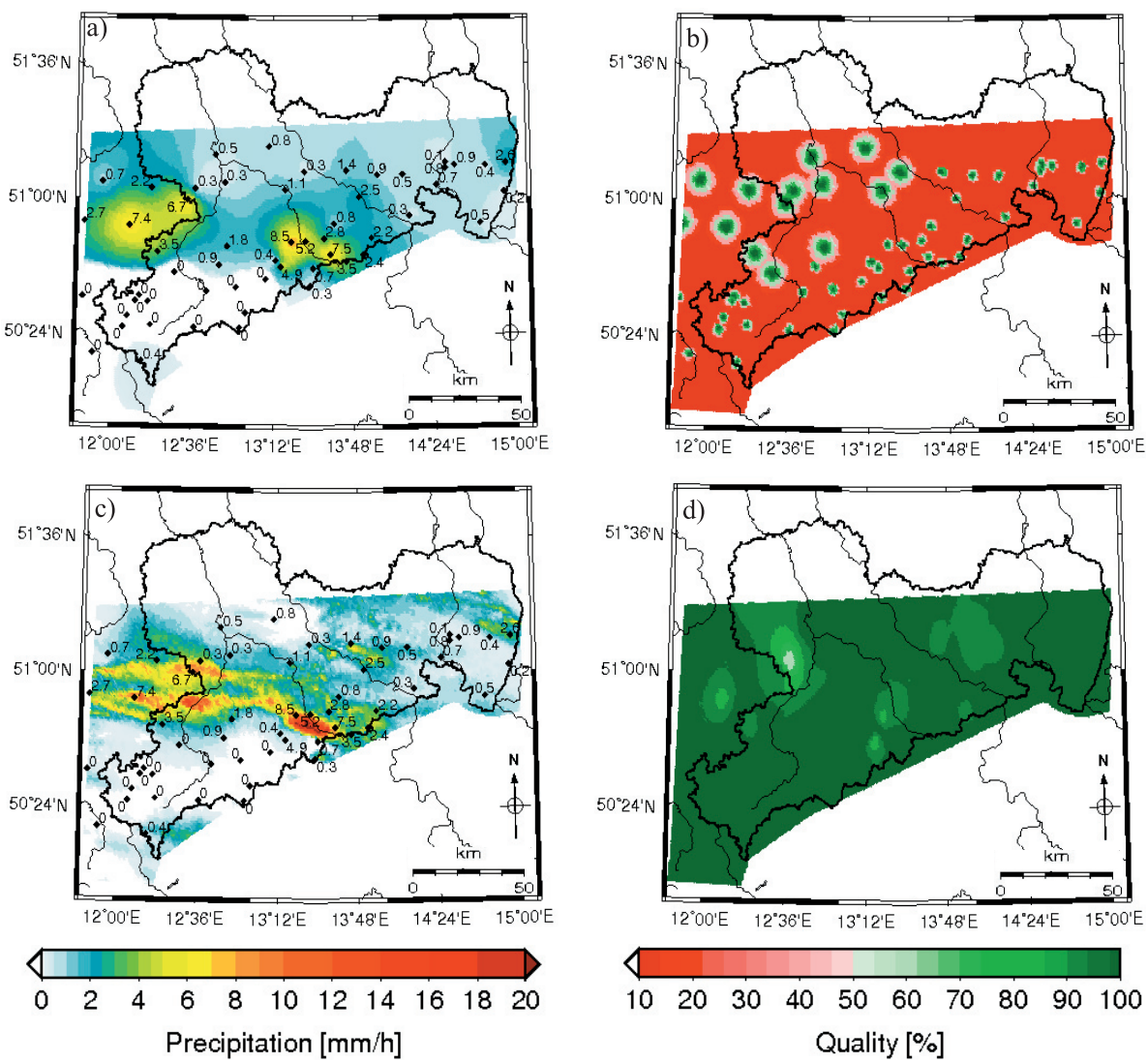

Fig. 11. Input fields (a) interpolated gauge observations and (c) hourly radar data, as well as (b) and (d) their corresponding quality fields for the advective event on 27 May 2006, 17:00 UTC.
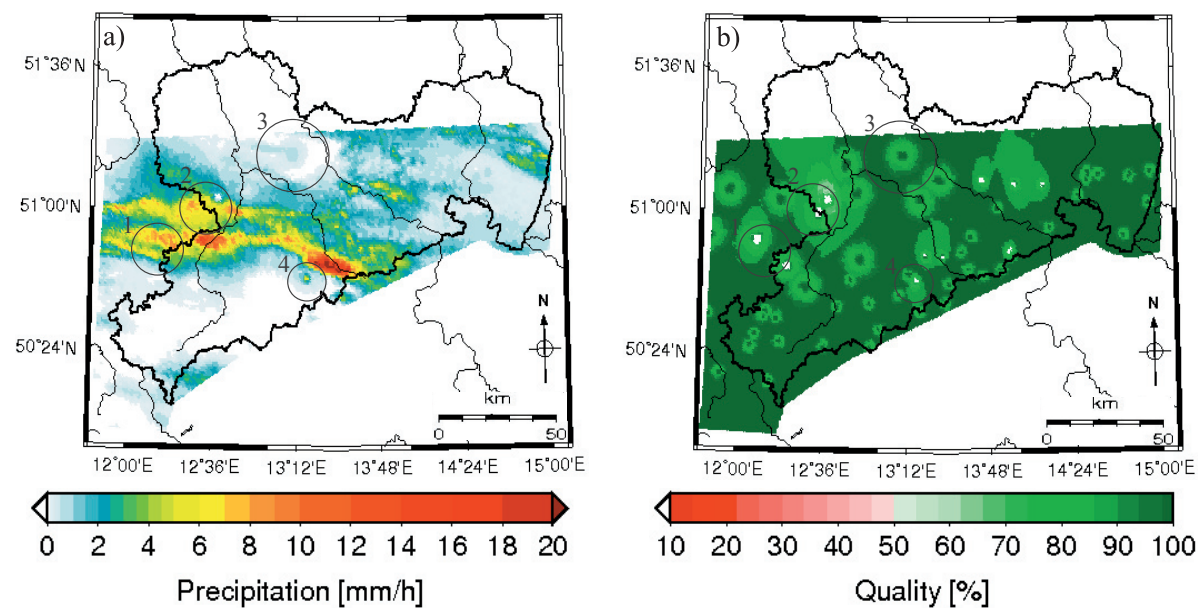

Fig. 12. Final precipitation (a) and quality (b) fields based on the combination of data with the cost function approach for the advective event on 27 May 2006, 17:00 UTC.

quality (tags 1,2 , and 4 ) resulted in a high weighting. As a consequence, the weighting rain rate was reduced, especially in the mountainous areas (tags 1 and 4), where radar detected higher precipitation amounts. An extension of rain area with lower intensity was achieved in the middle of the convective cell (tag 3 ), because radar was of low quality and further gauge precipitation data were available. 
Table 7. Bias ${ }_{\mathrm{CV}}$ and root-mean-squared error (RMSE) for the cross validation results based on pure interpolated gauge data (BGF-method), pure radar data and the combination of radar and gauge data for the investigated rain events.

\begin{tabular}{lclllll}
\hline Date & \multicolumn{2}{c}{ BGF-method } & \multicolumn{2}{c}{ Radar } & \multicolumn{2}{c}{$\begin{array}{c}\text { Combination } \\
\text { radar and BGF }\end{array}$} \\
\cline { 2 - 7 } & $\begin{array}{c}\text { Bias }_{C V} \\
{[\mathrm{~mm}]}\end{array}$ & $\begin{array}{l}\text { RMSE } \\
{[\mathrm{mm}]}\end{array}$ & $\begin{array}{l}\text { Bias }_{\mathrm{CV}} \\
{[\mathrm{mm}]}\end{array}$ & $\begin{array}{l}\text { RMSE } \\
{[\mathrm{mm}]}\end{array}$ & $\begin{array}{l}\text { Bias }_{\mathrm{CV}} \\
{[\mathrm{mm}]}\end{array}$ & $\begin{array}{l}\text { RMSE } \\
{[\mathrm{mm}]}\end{array}$ \\
\hline [UTC] & 0.00 & 0.32 & 0.25 & 1.19 & 0.25 & 1.18 \\
27 May 2006, 17:00 & -0.01 & 0.27 & 0.04 & 0.76 & 0.03 & 0.75 \\
27 May 2006, 18:00 & -0.36 & 3.23 & 2.14 & 9.41 & 2.11 & 9.31 \\
16 Jun 2006, 14:00 & -0.02 & 0.22 & 0.38 & 1.69 & 0.38 & 1.67 \\
16 Jun 2006, 15:00 & -0.02 & & & & & \\
\hline
\end{tabular}

The validation of combined precipitation product compared to pure interpolated rain or radar data is done by the use of cross validation (Sect. 3.4) and the parameters Bias $\mathrm{CV}$ and RMSE (Table 7). The two analysed consecutive hours for 16 of June 2006 are indentified as convective. They differ in the maximum of detected rain amounts and in the results of WAR and 10AR (recall Table 5). The spatial rainfall distribution for 14:00 UTC is more limited than for the subsequent hour, where the gauge station coverage of rain areas is higher. The cross validation performance criteria $\mathrm{Bias}_{\mathrm{CV}}$ and RMSE show, that the BGF interpolated rain fields define the mean precipitation and the higher rain intensities better than radar or the combined product. Radar values are highest. In general, the combined rain field represents a merged product of gauge and radar information, which is reflected by the mean Bias $\mathrm{CV}$ and RMSE values.

The results of $\mathrm{Bias}_{\mathrm{CV}}$ for two hours define an underestimation of average gauge measured precipitation with BGF value $\left(\mathrm{Bias}_{\mathrm{CV}}<0\right)$. Note, no adequate $\mathrm{BGFs}$ were available for both time steps and the interpolation was done with basic BGF. Radar and combined product overestimate average gauge measured rain $\left(\operatorname{Bias}_{\mathrm{CV}}>0\right)$. The high $\mathrm{RMSE}$ values show that the higher rain intensities are poorly captured for all cross validated data pairs.

The results of Bias $\mathrm{CV}$ and RMSE are influenced by the spatial limited areas of high rain amounts and low coverage of precipitation areas by gauge measurements. Gauge stations often measured marginal precipitation values at the fringe of the rain cell, while radar detected significant higher rain intensities (Fig. 10c). The investigation of $3 \times 3$ environment compensates this effect only slightly and the difference to the corresponding radar value is still high. The lower values of $\mathrm{Bias}_{\mathrm{CV}}$ and RMSE for 15:00 UTC indicate that the event is better presented by gauge and radar data than for the hour before.

The advective event on 27 May 2006, 17:00 UTC was characterized by an anticyclone, where several cells moved north-east and caused sporadic showers. Interpolated gauge data (Fig. 11a) were able to reproduce the rain band, which extended from west to east (Fig. 11c). The highest rain intensities of radar $\left(P_{\mathrm{r} \max }=25.3 \mathrm{~mm} / \mathrm{h}\right)$ were not observed by the gauges $\left(P_{\mathrm{g} \max }=8.53 \mathrm{~mm} / \mathrm{h}\right)$. The correlation between radar and gauge measurements was higher $(R=0.86)$ than for 16 June 2006. More extensive areas with higher gauge data quality can be figured out (Fig. 11b), because the representativeness of gauges was high. Gauge stations in mountainous areas represent the event up to a distance of $6 \mathrm{~km}$ and in lower situated areas up to $11 \mathrm{~km}$. The differences between radar and gauge data was lower, which is reflected in a higher quality of radar data than determined for the convective event (Fig. 11d).

The determined BIAS values fulfilled the criteria for the precipitation ranges two and three and showed only small tendencies to overestimate gauge data (recall Fig. 6). The HSS values for all ranges were higher than the prescribed threshold (Fig. 8). BIAS and HSS fulfil the threshold criteria and radar data were used to improve the estimation of rainfall in the immediate vicinity of the gauge stations. The final precipitation product reveals distinct spatial improvements (Fig. 12a). In the mountainous region, a gauge observed a higher intensity than radar (tag 4). The quality of the gauge value was high (Fig. 12b). Therefore, our analysis resulted in a local increase of rainfall. In the western part of Saxony the application of the cost-function resulted in a local reduction of radar rain amounts in areas with higher intensities (tags 1 and 2). Supplemental rain amounts were achieved in the north of the study area (tag 3 ), based on additional gauge information.

The precipitation areas for the two investigated hours of 27 May 2006 are well covered by gauge stations. Both time steps show similar results for maximum radar and gauge values as well as for WAR and 10AR. In comparison to the convective events, the investigation of $\mathrm{Bias}_{\mathrm{CV}}$ und RMSE (Table 7) shows similar results for the general performance. The absolute values are significant lower than for convective event. The interpolated data performed better than radar or 
combined results. Note, no basic but the same BGFs were used during cross validation process. Interpolated data determine areal precipitation well (Bias $\mathrm{CV}$ almost zero), where radar and combined product slightly overestimate. Highest rain rates are overestimated for all cross validated data. Once more, the combined product shows that the radar rain field was improved.

\section{Discussion and conclusions}

A real-time operating tool is presented to combine interpolated gauge and radar data. Focus was given to the precipitation type (convective or advective), to topographic distinct regions as well as the temporal and spatial variability of rainfall. The combined precipitation product can be provided for hydrologic modelling. In particular, the developed approach includes an analysis of rain event type based on radar measurements, a grid based assessment of gauge and radar data using statistical scores, the determination of quality fields for each data type and the combination of the derived rain and quality data by means of a cost function.

We classified the rainfall type based on the parameters WAR and 10AR, which are extracted from radar data (Ehret, 2003). The classification permitted a simple assignment of rain amounts to convective or advective rain events and was sufficient for the study requirements. The stability of established discrimination method was proved with stability indices from sounding data. The analysis showed a correct classification of $73 \%-76 \%$ for convective and $95 \%-97 \%$ for advective condition. For the hilly regions the accuracies are slightly lower, this is an evidence of the increasing influence of topographic effects (Kunz, 2007; Steinheimer and Haiden, 2007). The results are more reliable than the study presented by Dimitrova et al. (2009). Thus, we assume the presented classification using WAR and 10AR as sufficient for realtime processing.

Radar and gauge rain amounts were compared with the statistical parameters BIAS and HSS at the gauge sites. The underlying $2 \times 2$ contingency table was expanded to $3 \times 3$ (advective) and $4 \times 4$ (convective) to analyse the differences between gauge and radar rain amounts. The investigations were done for different precipitation ranges. In this context, we analysed the $3 \times 3$ neighbouring grid cells for appropriate radar values to find corresponding values. Generally, the BIAS results were not as expected. The analysis showed that an increasing rain rate associated with spatial limited rain areas and sparsely distributed gauge stations entails increasing differences between radar and gauge data. The presented results confirm with the study of Saulo and Ferreira (2003) and emphasised that rain events of low and high intensities are not equally detectable.

The investigations of three convective and three advective events showed an underestimation of radar rainfall for precipitation up to $0.1 \mathrm{~mm} / \mathrm{h}$ (range 1 ). Here, the comparison be- tween the BIAS values of a one hour time step to the average BIAS of short-time periods ( 8 hours) showed a decreasing value with increasing time scale. Ballester and Moré (2007) reported similar results for precipitation events between 0.2 and $0.4 \mathrm{~mm}$ for time scales between 12 and $36 \mathrm{~h}$. Our study confirmed with the known tendency of radar to underestimate gauge measurements for small rain rates. The HSS for convective rain was not as high as for advective events. The percentage of grid cells with hits (rain measured by radar and gauge) was lower than for advective events.

Generally, we confirm with Krajewski and Smith (2002) that influence of spatial and temporal variability of rainfall, sampling error mismatch of gauge and radar sensors were accumulated with higher rain rates. Gauge observations were often not representative for any of the nine radar pixels used. Jensen and Pedersen (2005) analysed the spatial variability of uncorrected gauge measured rainfall data for a single radar pixel $\left(0.25 \mathrm{~km}^{2}\right)$ for eight precipitation events and detected a variation up to $100 \%$ between the adjacent rain gauges (over a 4-day period). In the present study no general statistical score characteristic became apparent.

Interpolated gauge and radar data (rain and quality fields) were combined within a cost function, which was modified from a SOA (Pereira Fo and Crawford, 1999; Gerstner and Heinemann, 2008). Exemplarily, the efficiency of the method was shown for a convective and an advective event. The results presented an obvious influence of radar information, reflected by the good spatial data quality. The cost function was used to weight the input data, in dependence on their quality. We found out that the spatial quality of radar data was mostly better than for gauge measurements and resulted in a higher weighting. Pereira Fo and Crawford (1999) reported similar results for the hourly application of a SOA scheme to $2 \times 2 \mathrm{~km}^{2}$ grid cells, where radar data dominate the final product.

The combination of gauge and radar quality information within the cost function corrected the radar data with the help of ground measurements. Differing from our expectations, only local improvements were achieved for convective events. Here, a distinct reduction of false alert for local radar rainfall amounts in mountainous regions and an increase of reliability of rainfall area in flat regions were achieved. Gauge data increased as well as reduced the rain intensity in flat and mountainous regions for the advective event. Here, the improvements were of higher spatial dimension, caused by a higher spatial representativeness of gauge data.

The presented cost function was analysed by the means of cross validation. Pure interpolated gauge data, pure Radolan radar data and the combined data were analysed for a convective and an advective event at gauge sampling points. The BGF-method interpolated rain fields determined the lowest errors regarding the mean precipitation $\left(\right.$ Bias $\left._{\mathrm{CV}}\right)$ as well as higher rain intensities (RMSE) than corresponding radar or the combined product. We think that the main problem of 
the high differences relies on the analysis of sampling points and the low coverage of rain areas by gauge (mainly for convective events). Cross validation bases on the comparison of data pairs at the gauge stations, but do not consider the spatial variability in between. To infer the best method with cross validation would disregard the spatial information that enters from radar into the combination. For example in Fig. 9a and b it becomes apparent that a small rain cell in the western part was detected from radar, but not captured by gauges. Due to the additional radar information the cell appears in the combined product (Fig. 10a). The data give no evidence that radar data are of minor quality and therefore there are of high weighting (rain amount of the cell is similar to pure radar product). In general, the findings of cross validation show that the combined product merges benefits and disadvantages of both interpolated and radar data. It is obvious (e.g. Fig. 10a) that the combined product includes the small-scale variability of radar data. Our results confirm with the findings of Moszkowicz (2000), Bárdossy and Brommundt (2008) and Datta et al. (2003), where radar data are considered as a practical instrument to preserve the information of the small scale variability of precipitation. The studies showed high correlation values of radar data for low distances. We found similar characteristics by analysing our results visually. We regard the preservation of the small-scale rain variability as a benefit of the presented combination approach. For now, a statistical proof of these findings using the cross validation is missing, because it requires a large consistent data set of gauge and radar data, which were not available for the presented study.

Conclusions of our research:

1. The calculation of the parameters WAR and 10AR enable a simple, real-time rainfall classification based on radar information.

2. The statistical, grid based comparisons of gauge and radar data revealed a tendency of radar to underestimate low rain amounts and to overestimate high intensities. There are evidences to suggest, that with increasing rain rates (followed by a decreasing extension of cell) gauge stations were not able to detect highest rain amounts as given by radar measurements.

3. The knowledge of the precipitation type allows a specific consideration of precipitation data and quality within the weighting procedure. Nevertheless, the applied cost function showed congruence between radar information in the final precipitation field, because the assigned spatial quality of radar data was distinct better than the quality of gauge data.

4. The proposed combination method merges the benefit and disadvantages of pure interpolated and pure radar data and leads to mean estimates. The product combines the benefit of accurate gauge measurements and the spatial distribution of rainfall given by radar and comprehends the uncertainties of BGF interpolations (to be bound to the number of gauge stations) as well as the overestimation of high rain rate by radar.

5. The combination of rain and quality fields using the cost function produces distinct improvements for advective events. For convective rainfalls, only very local changes were achieved.

6. The correlation between radar and gauge data determines the final product quality. The results show that the number of gauge stations is crucial in this context. Thus, the application of the cross validation as an objective performance criteria is limited by the insufficient number of gauge stations. It complicates the final conclusion, whether the use of the BGF method should be preferred to the presented method of data combination. The visual analyses showed that the use of the presented cost function avoids false rainfall amounts in areas of low input data quality and improves the reliability in areas of high data quality.

7. Cross validation should not be used as the only performance criteria, because it does not take into account the small scale variability of radar and the combined product. Since no further objective performance measures were calculated in the study, presented findings could only be drawn based on cross validation results. The major benefit of our combination approach is the consideration of spatial heterogeneity of highly resolved precipitation fields.

Further research should be focused to the established quality fields and their influence to the cost function. For radar data, we expect an overestimation of dynamic quality, if only a few values are available for interpolation. Hence, a combination of static and dynamic radar quality should be analysed. Furthermore it should be analysed, whether the criteria for the dynamic radar quality field should be adapted to convective and advective events. The used quality field of gauge data could be enhanced with additional information from the interpolation method; for instance the assignment of cross validation results.

The tendency of radar data to underestimate gauge values for smaller rain intensities has to be analysed in detail, e.g. with focus on the ranges of established convective and advective precipitation ranges. That could entail a combination of several precipitation ranges (decreasing the number of ranges for both event types). The precipitation range 1 has to be modified with regard to the limitation of radar measurements for small rain rates. Further investigations should analyse the application of presented method for more spatial limited convective events, e.g. within a net of higher station density in Saxony. In this context, the time lack of $10 \mathrm{~min}$ between radar and gauge data should be analysed. 
The weighting of different precipitation and quality data within the cost function depending on the precipitation type should be analysed for further events. Maybe the applied radar weighting (especially for convective events) was too high and a reduction is required.

The combination of radar and gauge data within the cost function resulted in average and indicated the merging of benefits and disadvantages of both sources. The cross validation did not reveal the high spatial variability of radar data. We think a rainfall-runoff model is a useful tool to check the results of the presented method. A first validation of the final rain product was initiated by Pluntke et al. (2010). The results of this study are slightly contrary to the findings of Kneis and Heistermann (2009), where interpolated gauge data performed better than radar data. We think that only a long term analysis with the proposed methods will allow a final evaluation of them.

Acknowledgements. The authors would like to thank the German Weather Service and the Saxon State Ministry of the Environment and Agriculture for providing the data as well as the State Environment Agency Rheinland-Pfalz for providing the interpolation tool InterMet. We would like to thank the reviewers for the helpful advices and comments, which allowed improving considerably the paper. We are grateful to Antje Tittebrand, Janine Kallenbach as well as Klemens Barfus for their constructive comments and their support for preparing that paper.

This research is part of the project "Determination of extreme rainfall for small and medium size catchment basins at low mountain ranges in real time with increased redundancy (EXTRA)". The project was funded by the Federal Ministry of Education and Research (promotional reference 0330700A).

Edited by: M. Disse

Reviewed by: U. Ehret and another anonymous referee

\section{References}

Alcamo, J., Moreno, J. M., Nováky, B., Bindi, M., Corobov, R., Devoy, R. J. N., Giannakopoulos, C., Martin, E., Olesen, J. E., and Shvidenko, A.: Europe. Climate Change 2007: Impacts, Adaptation and Vulnerability, in: Contribution of Working Group II to the Fourth Assessment Report of the Intergovernmental Panel on Climate Change, edited by: Parry, M. L., Canziani, O. F., Palutikof, J. P., van der Linden, P. J., and Hanson, C. E., Cambridge University Press, Cambridge, UK, 541-580, 2007.

Aniol, R. and Riedl, J.: Quantitative RadarFlächenniederschlagsmessung: Problematik and praktische Erfahrungen, Meteorol. Rundsch., 32, 116-127, 1979 (in German).

Ballester, J. and Moré, J.: The representativeness problem of a station net applied to the verification of a precipitation forecast based on areas, Meteorol. Appl., 14, 177-184, 2007.

Bárdossy, A. and Brommundt, J.: Erzeugung simultansynthetischer Niederschlagsreihen in hoher zeitlicher und räumlicher Auflösung für Baden-Württemberg, Forschungsbericht FZKA-BWPLUS, 2008 (in German).
Bartels, H.: Projekt RADOLAN. Routineverfahren zur OnlineAneichung der Radarniederschlagsdaten mit Hilfe von automatischen Bodenniederschlagsstationen (Ombrometer), ProjektAbschlussbericht, available at: http://www.dwd.de (search for: Radolan) (last access: 24 January 2010), 2004 (in German).

Bartels, H., Dietzer, B., Malitz, G., Albrecht, F. M., and Guttenberger, J.: KOSTRA-DWD-2000 - Starkniederschlagshöhen für Deutschland (1951-2000), Eigenverlag Deutscher Wetterdienst, Offenbach a. M., 2005 (in German).

Berne, A., Delrieu, G., Creutin, J.-D., and Obled, C.: Temporal and spatial resolution of rainfall measurements required for urban hydrology, J. Hydrol., 299, 166-179, 2004.

Bernhofer, C., Goldberg, V., Franke, J., Häntzschel, J., Harmansa, S., Pluntke, T., Geidel, K., Surke, M., Prasse, H., Freydank, E., Hänsel, S., Mellentin, U., and Küchler, W.: Sachsen im Klimawandel - Eine Analyse. Sächsisches Staatsministerium für Umwelt und Landwirtschaft, Eigenverlag, Dresden, 2008 (in German).

Borga, M., Tonelli, F., Moore, R. J., and Andrieu, H.: Long-term assessment of bias adjustment in radar rainfall estimation, Water Resour. Res., 38(11), 1226, doi:10.1029/2001WR000555, 2002.

Bouttier, F. and Courtier, P.: Data Assimilation concepts and methods, ECMWF Meteorological Training Course Lecture Series, 2002.

Cherubini, T., Ghelli, A., and Lalaurette, F.: Verification of Precipitation Forecasts over the Alpine Regions Using a High-Density Observing Network, Weather Forecast., 17, 238-249, 2002.

Collier, C. G.: The Impact of Wind Drift on the Utility of Very High Spatial Resolution Radar Data Over Urban Areas, Phys. Chem. Earth, 24, 889-893, 1999.

Curtis, D. C.: Inadvertent Rain Gauge Inconsistencies and Their Effect on Hydrologic Analysis, California-Nevada ALERT Users Group Conference, Ventura, CA, 15-17 May 1996.

Datta, S., Jones, W. L., Roy, B., and Tokay, A.: Spatial Variability of Surface Rainfall as Observed from TRMM Field Campaign Data, J. Appl. Meteorol., 42, 598-610, 2003.

Delrieu, G., Andrieu, H., and Creutin, J.-D.: Quantification of PathIntegrated Attenuation for X- and C-Band Weather Radar Systems Operating in Mediterranean Heavy Rainfall, J. Appl. Meteorol., 39, 840-850, 2000.

Deutscher Wetterdienst (DWD): DWD Jahresbericht 1980, Eigenverlag Deutscher Wetterdienst, Offenbach a. M., 1981 (in German).

Dimitrova, T., Mitzeva, R., and Savtchenko, A.: Environmental conditions responsible fort he type of precipitation in summer convective storms over Bulgaria, Atmos. Res., 93, 30-38, 2009.

Ehret, U.: Rainfall and Flood Nowcasting in Small Catchments using Weather Radar, Mitteilungen des Instituts für Wasserbau Universität Stuttgart, 2003.

Fuchs, T., Rapp, J., Rubel, F., and Rudolf, B.: Correction of synoptic precipitation observations due to systematic measuring errors with special regard to precipitation phases, Phys. Chem. Earth, 29(9), 689-693, 2001.

Gebremichael, M. and Krajewski, W. F.: Assessment of the Statistical Characterization of Small-Scale Rainfall Variability from Radar: Analysis of TRMM Ground Validation Datasets, J. Appl. Meteorol., 43, 1180-1199, 2004.

Germann, U. and Joss, J.: Variograms of Radar Reflectivity to Describe the Spatial Continuity of Alpine Precipitation, J. Appl. 
Meteorol., 40, 1042-1059, 2001.

Germann, U., Berenguer, M., Sempere-Torres, D., and Zappa, M.: REAL - Ensemble radar precipitation estimation for hydrology in a mountainous region, Q. J. R. Meteor. Soc., 135, 445-456, 2009.

Gerstner, E.-M. and Heinemann, G.: Real-time areal precipitation determination from radar by means of statistical objective analysis, J. Hydrol., 352, 296-308, 2008.

Haase, G. and Mannsfeld, K.: Naturraumeinheiten, Landschaftsfunktionen und Leitbilder am Beispiel von Sachsen, Forschungen zur deutschen Landeskunde, 250, Selbstverlag, Flensburg, 214 S., 2002 (in German).

Haberlandt, U., Schumann, A., and Büttner, U.: Räumliche Niederschlagsschätzung aus Punktmessungen und Radar am Beispiel des Elbehochwassers 2002, Hydrologie und Wasserwirtschaft, 49(2), 56-67, 2005 (in German).

Harrison, D. L., Driscoll, S. J., and Kitchen, M.: Improving precipitation estimates from weather radar using quality control and correction techniques, Meteorol. Appl., 6, 135-144, 2000.

Hinterding, A.: Entwicklung hybrider Interpolationsverfahren für den automatisierten Betrieb am Beispiel meteorologischer Größen, Inst. f. Geoinformatik, Westfälische WilhelmsUniversität Münster, IfGIprints, 19, Münster, 2003 (in German).

Houze Jr., R. A.: Stratiform Precipitation in Regions of Convection: A Meteorological Paradox?, B. Am. Meteorol. Soc., 2179-2196, 1997.

Jensen, N. E. and Pedersen, L.: Spatial variability of rainfall. Variations within a single radar pixel, Atmos. Res., 77, 269-277, 2005.

Krajewski, W. F. and Smith, J. A.: Radar hydrology: rainfall estimation, Adv. Water Resour., 25, 1387-1394, 2002.

Krämer, S.: Quantitative Radardatenaufbereitung für die Niederschlagsvorhersage und die Siedlungsentwässerung, Inst. F. Wasserwirtschaft, Hydrologie und landwirtschaftlichen Wasserbau, Gottfried Wilhelm Leibnitz Universität Hannover, Mitteilungen, 92, Hannover, 2008 (in German).

Kunz, M.: The skill of convective parameters and indices to predict isolated and severe thunderstorms, Nat. Hazards Earth Syst. Sci., 7, 327-342, 2007,

http://www.nat-hazards-earth-syst-sci.net/7/327/2007/.

Michelson, D. B.: Systematic correction of precipitation gauge observations using analysed meteorological variables, J. Hydrol., 290, 161-177, 2004.

Moreau, E., Testud, J., and Le Bouar, E.: Rainfall spatial variability observed by X-band weather radar and its implication for the accuracy of rainfall estimates, Adv. Water Resour., 32, 1011-1019, 2009.

Moszkowicz, S.: Small-Scale Structure of Rain Field- Preliminary Results Basing on a Digital Gauge Network and on MRL-5 Legionowo Radar, Phys. Chem. Earth Pt. B, 25(10-12), 933-938, 2000.

Nešpor, V. and Sevruk, B.: Estimation of Wind-Induced Error of Rainfall Gauge Measurements using a Numerical Simulation, J. Atmos. Ocean. Tech., 16, 450-464, 1999.

Peppler, R. A.: A review of static stability indices and related thermodynamic parameters, Illinois State Water Survey Division, Climate and Meteorology Section, SWS Miscellaneous Publication, 1988.

Pereira Fo, A. J. and Crawford, K. C.: Mesoscale Precipitation Fields. Part 1: Statistical Analysis and Hydrologic Response, J.
Appl. Meteorol., 38, 82-100, 1999.

Pineda, N., Rigo, T., Bech, J., and Soler, X..: Lightning and precipitation relationship in summer thunderstorms: Case study in the North Western Mediterranean region, Atmos. Res., 85, 159-170, 2007.

Pluntke, T., Jatho, N., Kurbjuhn, C., Dietrich, J., and Bernhofer, C.: Use of past precipitation data for regionalisation of hourly rainfall in the low mountain ranges of Saxony, Germany, Nat. Hazards Earth Syst. Sci., 10, 353-370, 2010, http://www.nat-hazards-earth-syst-sci.net/10/353/2010/.

Queralt, S., Hernandez, E., Gallego, D., and Lorente, P.: Mesoscale convective systems in Spain: instability conditions and moisture sources involved, Adv. Geosci., 16, 81-88, 2008, http://www.adv-geosci.net/16/81/2008/.

Quirmbach, M.: Nutzung von Wetteradardaten für Niederschlagsund Abflussvorhersage in urbanen Einzugsgebieten, Dissertation, Schriftenreihe Hydrologie/Wasserwirtschaft, Heft 19, Lehrstuhl fr Hydrologie, Wasserwirtschaft und Umwelttechnik, Ruhr-Universitt Bochum, ISSN 0949-5975, 2003 (in German).

Rinehart, R. E.: Radar for Meteorologists, 4th edn., Columbia, 2004.

Sánchez, J. L., Fernández, M. V., Fernández, J. T., Tuduri, E., and Ramis, C.: Analysis of mesoscale convective systems with hail precipitation, Atmos. Res., 67-68, 573-588, 2003.

Saulo, A. C. and Ferreira, L.: Evaluation of quantitative precipitation forecasts over southern South America, Aust. Meteorol. Mag., 52, 81-93, 2003.

Sempere-Torres, D., Sánchez-Diezma, R., Zawadzki, I., and Creutin, J. D.: Identification of Stratiform and Convective Areas Using Radar Data with Application to the Improvement of DSD Analysis and Z-R-Relations, Phys. Chem. Earth Pt. B, 25(1012), 985-990, 2000.

Seo, D.-J. and Breitenbach, J. P.: Real-Time Correction of Spatially Nonuniform Bias in Radar Rainfall Data Using Rain Gauge Measurements, J. Hydrometeorol., 3, 93-111, 2002

Sevruk, B.: Niederschlag als Wasserkreislaufelement, Theorie und Praxis der Niederschlagsmessung, Zürich-Nitra, 2004 (in German).

Sokol, Z.: The use of radar and gauge measurements to estimate areal precipitation for several Czech river basins, Stud. Geophys. Geod., 47, 587-604, 2003.

Steinheimer, M. and Haiden, T.: Improved nowcasting of precipitation based on convective analysis fields, Adv. Geosci., 10, 125131, 2007, http://www.adv-geosci.net/10/125/2007/.

Van der Velde, O.: Guide to using Convective Weather Maps, available at: www.lightningwizard.com(last modified: August 2007), 2007.

Villarini, G., Mandapaka, P. V., Krajewski, W. F., and Moore, R. J.: Rainfall and sampling uncertainties: a rain gauge perspective, J. Geophys. Res. Atmos., 113, D11102, doi:10.1029/2007JD009214, 2008.

Villarini, G. and Krajewski, W.: Review of the Different Sources of Uncertainty in Single Polarization Radar-Based Estimates of Rainfall, Surv. Geophys., 31(1), 107-129, doi:10.1007/s10712009-9079-x, 2010.

Wergen, W.: Datenassimilation - Ein Überblick, Promet, 3(4), 142149, 2002 (in German).

Wilks, D.: Statistical Methods in the Atmospheric Sciences, 2nd edn., Cornell, 2006. 